\title{
The Safety of Cruciferous Plants in Humans: A Systematic Review
}

\author{
Ori Scott, ${ }^{1}$ Elaine Galicia-Connolly, ${ }^{2}$ Denise Adams, ${ }^{2}$ Soleil Surette, ${ }^{2}$ \\ Sunita Vohra, ${ }^{2,3}$ and Jerome Y. Yager ${ }^{1}$ \\ ${ }^{1}$ Pediatric Neurosciences, Department of Pediatrics, Stollery Children's Hospital, University of Alberta, Room 3-469, \\ Edmonton Clinic Health Academy (ECHA), 11405-87 Avenue, Edmonton, AB, Canada T6G 1C9 \\ ${ }^{2}$ CARE Program, Department of Pediatrics, University of Alberta, Edmonton Clinic Health Academy (ECHA), 11405-87 Avenue, \\ Edmonton, AB, Canada T6G 1C9 \\ ${ }^{3}$ School of Public Health, University of Alberta, Edmonton Clinic Health Academy (ECHA), 11405-87 Avenue, \\ Edmonton, AB, Canada T6G 1C9
}

Correspondence should be addressed to Jerome Y. Yager, jyager@ualberta.ca

Received 27 July 2011; Accepted 11 October 2011

Academic Editor: Ikhlas A. Khan

Copyright ( $) 2012$ Ori Scott et al. This is an open access article distributed under the Creative Commons Attribution License, which permits unrestricted use, distribution, and reproduction in any medium, provided the original work is properly cited.

\begin{abstract}
Some cruciferous plants may serve as preventive treatments for several medical conditions; our objective was to systematically investigate their safety in humans. Four electronic databases were searched, and, of 10,831 references identified, 50 were included. Data were extracted by two independent reviewers, whereafter the association between interventions and adverse events was assessed. Adverse events in 53 subjects were identified through clinical trials; of these, altered drug metabolism was rated as certainly/ likely caused by cruciferous plants. Adverse events in 1247 subjects were identified through observational studies, of which none received high causality ratings. Adverse events in 35 subjects were identified through case reports, of which allergies and warfarin resistance were rated as certainly/likely caused by cruciferous plants. We conclude that cruciferous plants are safe in humans, with the exception of allergies. Individuals treated with warfarin should consult their physician. Further investigation of uses of cruciferous plants in preventative medicine is warranted.
\end{abstract}

\section{Introduction}

In the last decade, a rapid rise in the demand for natural health products has become evident. This prominent trend stems from increasing awareness of the potential for significant adverse effects caused by pharmacologic interventions, along with a growing interest in preventive medicine strategies [1].

A group of plants that has been shown to possess strong anti-inflammatory and antioxidative abilities is the cruciferous plants of the Brassica genus. Brassica is a genus of plants in the Brassicaceae family. Vegetables of the family Brassicaceae (also called Cruciferae) are generally referred to as cruciferous vegetables. These vegetables are widely cultivated, with many genera, species, and cultivars being raised for food production. The most common Brassica vegetables eaten by people are in a single species (B. oleracea), including kale, collard greens, cabbage, Brussels sprouts, kohlrabi, broccoli, and cauliflower. Numerous other species in the genus are also edible such as mustard (B. nigra), Chinese cabbage (B. rapa), and oilseed rape (B. napus; sometimes referred to as "rapeseed oil" or "canola") [2].

Some members of this group have received wide acclaim as potential natural preventers or attenuators of several health conditions such as coronary artery disease, gastritis, and cancer [3-8]. Recent studies reveal that these therapeutic effects may extend to the fetus as well: an international casecontrol study showed that maternal consumption of cruciferous vegetables during pregnancy decreases the risk of childhood anaplastic astrocarcinomas [9]; a study in rats found that offspring of spontaneously hypertensive rats that consumed broccoli sprouts during gestation had lower blood pressure and reduced markers of oxidative stress and inflammation, compared to controls [10].

The impetus for this systematic review stems from work done in our laboratory that has shown the potential benefit of supplementing the diet of pregnant dams with broccoli sprouts in preventing perinatal brain injury. In this regard, 
TABLe 1: Eligibility criteria and data extracted ${ }^{1}$.

\begin{tabular}{lll}
\hline PICOS & Eligibility criteria & Data extracted \\
\hline Patient & All human subjects were included & $\begin{array}{l}\text { Age, concurrent medical conditions and } \\
\text { treatments, reason for intervention (where } \\
\text { relevant) }\end{array}$ \\
$\begin{array}{ll}\text { Intervention } \\
\text { to cruciferous plants, their derivatives, or their } \\
\text { constituents } \\
\text { Reports with or without a comparator group. } \\
\text { Reports without control groups were included in } \\
\text { order to include all potential adverse events }\end{array}$ & $\begin{array}{l}\text { Plant or substance exposed to, route of exposure, } \\
\text { duration of exposure, dose (if available) }\end{array}$ \\
Comparators & $\begin{array}{l}\text { Numbers in the intervention and comparator } \\
\text { groups (when relevant) }\end{array}$ \\
Outcome & $\begin{array}{l}\text { Presence or absence of adverse events, description } \\
\text { of adverse event, acute management of adverse } \\
\text { event (for case reports), outcome (when } \\
\text { available), and causality }\end{array}$ \\
Study design & $\begin{array}{l}\text { All study designs which were relevant to the } \\
\text { languages were included and translated when } \\
\text { necessary }\end{array}$ & Type of study design and setting
\end{tabular}

we have established a model of chronic placental insufficiency that results in fetal growth restriction and damage to the white matter of the brain, reminiscent of periventricular leukomalacia, the anatomic hallmark of cerebral palsy. Supplementing the maternal diet during the last trimester of pregnancy and first weeks of infant nutrition prevented the white matter injury and accompanying behavioural deficits in the offspring. These findings suggest, for the first time, a safe and efficacious approach to the prevention of developmental disability and cerebral palsy [11]. In order to provide the background in which to determine whether this therapy would be acceptable for humans, a thorough determination of the safety of the cruciferous species of plants in humans is necessary.

Researchers now believe that the key to the therapeutic abilities of cruciferous plants is their high content of phase2 enzyme inducers such as sulforaphane, which induce the transcription of genes found under the control of the antioxidant response element (ARE). This causes an upregulation of the endogenous antioxidant glutathione, crucial to the cell's ability to withstand oxidative stress [12-14].

Several reviews evaluated the safety and health benefits of some components of cruciferous plants, such as indole3-carbinol and isothiocyanates, and found them safe for humans $[15,16]$. However, to our knowledge, a systematic review evaluating the safety of cruciferous plants, namely, the degree of certainty that they would not cause any adverse effects, has not yet been published.

The purpose of this paper is to systematically collect and synthesize all published reports of human adverse events associated with exposure to cruciferous plants. This approach of analyzing safety of a multi-ingredient natural product is especially important when considering consumption of the whole plant as a therapeutic means, as opposed to treatment with an isolated component or metabolite of a plant.

\section{Methods}

This systematic paper was undertaken in line with the relevant criteria of the PRISMA (Preferred Reporting Items for Systematic Reviews and Meta-Analyses) statement [17]. The following methods used in the systematic review, including identification, screening, eligibility criteria, inclusion, and data extraction, were agreed upon by the authors a priori.

References were identified through comprehensive search strategies, which were developed in conjunction with a research librarian. An electronic search of the following four databases was performed: Medline, Embase, Pascal, and IPA (International Pharmaceutical Abstracts), from inception to July 2010, irrespective of language. The following search terms were used: isothiocyanate, Brassica, cruciferous, glucoraphanin, sulforaphane, broccoli, kale, cabbage, cauliflower, collard green, Brussels sprout. MESH headings and keywords were searched, and truncation was used as needed. A list of the search strategies is available as supplemental material available online at doi: 10.1155/2012/503241.

The research question and eligibility criteria were developed by using PICOS (patient, intervention, comparators, outcome, study design). The inclusion criteria were any studies reporting original data, addressing safety of cruciferous plants, their derivatives, or their constituents, to humans. Details of the eligibility criteria are reported in Table 1.

The references were imported into a bibliographic database (RefWorks). Titles and abstracts of identified studies were independently screened by two reviewers. Full texts for potentially relevant studies were obtained and reviewed for inclusion based on predetermined criteria. Disagreement was resolved by consensus, and if necessary a third party was consulted (JYY).

Data was extracted by two independent reviewers, using standardized forms. Disagreement was resolved by consensus. Data relating to the patient or group, the intervention, 
the comparator group (where relevant), the outcomes measured (adverse events or lack thereof), and the study design were extracted as detailed in Table 1.

The degree of association between the intervention and the adverse event was independently assessed by the two reviewers using the Causality Algorithm used by Health Canada and the WHO Collaborating Centre for International Drug Monitoring (Health Canada 2009). Categories for assessment were certainly, likely, possibly, unlikely, conditional/unclassified, and Unassessible/Unclassifiable. Disagreement between reviewers was resolved by discussion. Guidelines used to assess causality are available as supplemental material.

The studies were finally categorized into 3 groups: (1) trials, (2) observational studies, and (3) case reports. Studies were classified as controlled clinical trials when involving one or more test treatments, at least one control treatment, specified outcome measures for evaluating the studied intervention, and when the method for assigning patients to the test treatment was not a mathematical randomization technique. Randomized controlled trials, on the other hand, were defined as studies in which randomization using mathematical techniques, such as the use of a random numbers table, is employed to assign patients to test or control treatments. Studies were classified as single-case experimental design trials when the subjects served as his/her own control, rather than using another individual or a group.

We did not perform a meta-analysis as the inclusion criteria for subjects, interventions, clinical outcomes, and study designs were very heterogeneous; conducting a meta-analysis using these data would not have been appropriate.

\section{Results}

3.1. Study Characteristics. Searches resulted in a total of 10,831 references. After screening of titles and abstracts, the full texts of 367 articles were obtained. Of these, 50 articles met all inclusion criteria. Of the total included publications, 45 were published in English, 2 were published in German, and one each was published in Italian, French, and Spanish.

Articles were excluded for the following reasons: not human subjects (210), not evaluating adverse effects or lack thereof (21), intervention or substance exposure does not include cruciferous plants (2), not presenting original data (47). Thirty-seven articles discussing toxic oil syndrome (37) were excluded post hoc for reasons presented below.

Of the 50 included studies, 13 were trials (6 single-case experimental design trials, 4 controlled clinical trials, and 3 randomized control trials (RCTs)), 13 were observational studies ( 7 cohort studies, 3 case-control studies, 2 cross-sectional studies, and 1 qualitative survey), and 24 were case reports (Figure 1).

3.2. Trials. Thirteen trials were included, reporting adverse events in 53/496 patients (10.7\%) [18-30]. Three of them were randomized controlled trials (RCTs), 4 were controlled clinical trials, and 6 were single-case experimental design (SCED) trials. Six of the trials were classified as safety trials, meaning that their stated primary aim was to assess safety of interventions [18-23], whereas 7 were nonsafety trials which evaluated efficacy of interventions but also reported adverse events [24-30] (Table 2).

The safety trials [18-23] included 1 RCT, 1 controlled clinical trial, and 4 SCED trials. The only safety RCT was a double-blinded trial in 12 healthy subjects, ages $28-57$, of whom 9 consumed daily doses of broccoli sprout extract combined with myrosinase (an enzyme found in all Brassica which converts glucosinolates to active isothiocyanates) over a period of 7 days. Extracts contained $25 \mu \mathrm{mol}$ glucosinolate, $100 \mu \mathrm{mol}$ glucosinolate, or $25 \mu \mathrm{mol}$ isothiocyanate. No adverse events were reported [18].

The second safety trial was a double-blind controlled clinical trial in 76 subjects, ages 3-39. Thirty-eight subjects had a reported mustard allergy, and 38 age- and gender-matched controls suffered from dust-mite allergy but had no mustard allergy. Both groups underwent food challenges with mustard and a variety of other allergens. Of the 38 patients, 14 had a positive mustard challenge, of which 12 had oral allergy syndrome (pruritus, mild angioedema of lips, tongue, and throat), 1 had more severe angioedema with bronchial asthma, and 1 had systemic anaphylaxis. It is important to mention that of the 38 patients, 35 were atopic (including rhinitis, and/or bronchial asthma, atopic dermatitis) [19].

The last four safety trials were all single-case experimental design trials (SCED). The first was a trial in 10 healthy subjects, ages 21-30, which strived to determine the effect of cruciferous vegetables on phenacetin and antipyrine metabolism. Subjects started by consuming a control diet for 13 days, after which they were placed on a diet containing $300 \mathrm{~g} /$ day of Brussels sprouts and $200 \mathrm{~g} /$ day of cabbage over a period of 7 days, and finally returned to the control diet for the last 10 days. In parallel, every morning the subjects were given either $900 \mathrm{mg}$ of phenacetin or $1.8 \mathrm{mg} / \mathrm{kg}$ of antipyrine. The mean plasma concentrations of either drug were measured at different intervals after administration. Researchers found that the cruciferous diet enhanced the phenacetin metabolism in the gastrointestinal tract and/or during its first pass in the liver, increasing its rate of elimination. No changes in antipyrine metabolism were noted [20]. It is worth noting that the US Food and Drug Administration ordered the withdrawal of drugs containing phenacetin in November 1983, owing to its carcinogenic and kidney-damaging properties (Federal Register of October 5, 1983 (48 FR 45466)).

The second SCED trial included 10 healthy subjects, ages 23-35, and aimed to determine the effect of cruciferous vegetables on acetaminophen and oxazepam metabolism. Subjects started by consuming a control diet for 10 days, after which they were put on a diet containing $300 \mathrm{~g} / \mathrm{day}$ of Brussels sprouts and $200 \mathrm{~g} /$ day of cabbage over a period of 10 days, and finally returned to the control diet for the last 10 days. In parallel, every morning the subjects were given either $45 \mathrm{mg}$ of oxazepam or $1500 \mathrm{mg}$ of acetaminophen. The mean plasma concentrations of either drug were measured at different intervals after administration, and a $24 \mathrm{~h}$ urinary recovery of conjugates was performed. Researchers found that the cruciferous diet enhanced the acetaminophen metabolism and glucuronide conjugation; however, they mention 


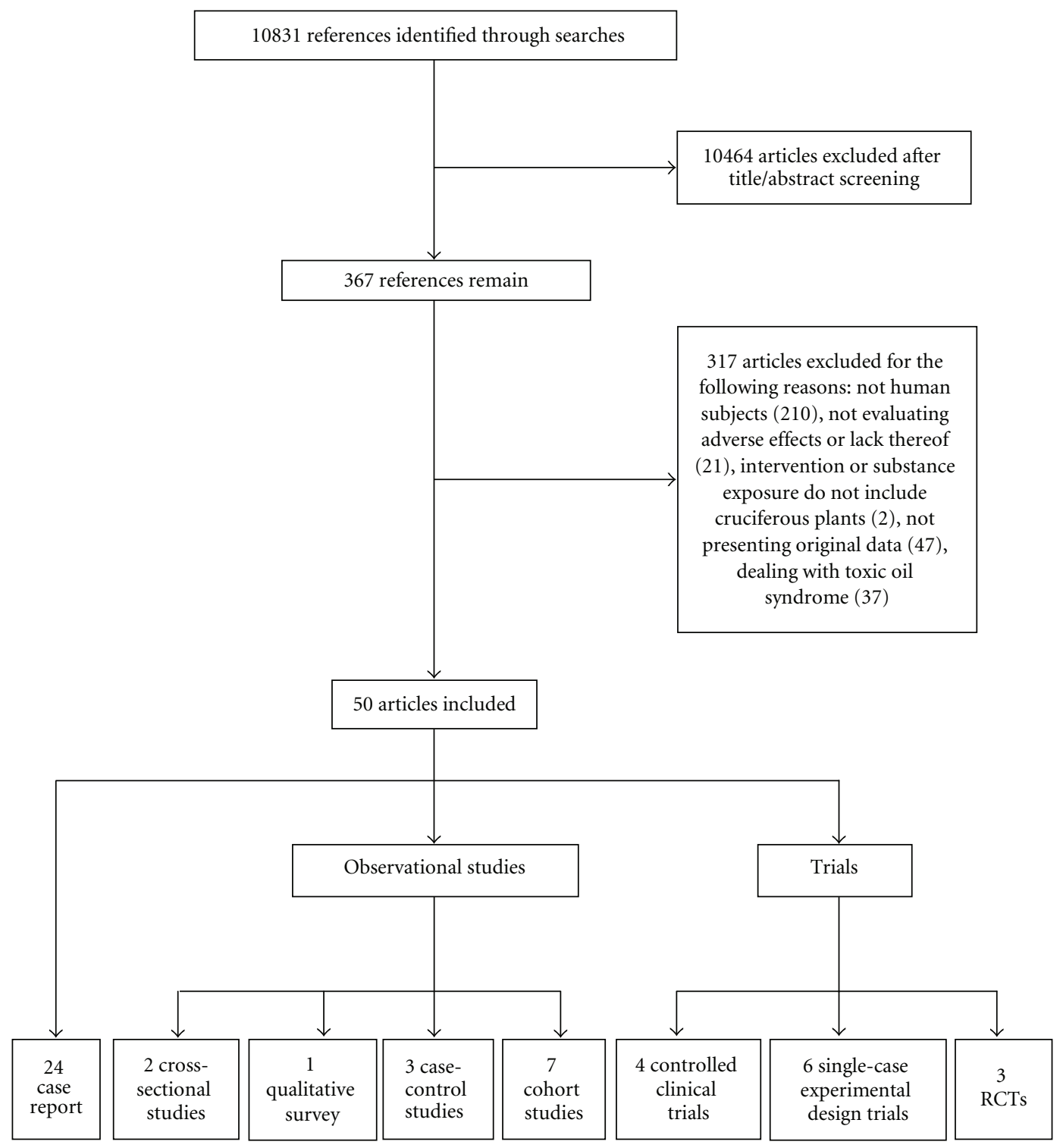

FIGURE 1: PRISMA (Preferred Reporting Items for Systematic Reviews and Meta-Analyses) flow diagram of study identification, inclusion, and exclusion.

that the decreased levels of cysteine conjugate in urine actually indicate reduced toxicity. No changes in oxazepam metabolism were noted [21].

The third safety SCED trial included 10 healthy subjects, ages 22-40; the goal of this study was to determine the effect of a diet rich in Brussels sprouts on warfarin metabolism. Subjects consumed their customary diets for 3 days and were then instructed to consume $400 \mathrm{~g} /$ day of Brussels sprouts for the next 18 days. Warfarin administration $(20 \mathrm{mg})$ was provided twice on days 1 and 18. Mean plasma concentrations of warfarin were measured at different time periods, as well as prothrombin activity, and clearance rates were calculated. Researchers showed that the diet had resulted in accelerated warfarin metabolism and decreased anticoagulation [22].

The last safety SCED trial included 6 subjects, ages 20-38, with a history of recurrent allergic reactions to consumption of raw cabbage. This study aimed to determine the sensitivity profile of such patients to other cruciferous vegetables (cauliflower, mustard, and broccoli), as well as to cooked versus raw cabbage. Skin prick tests were performed for a variety of allergens; later, food challenges were performed with cooked cabbage, and levels of cabbage-specific IgE were measured in patients' sera. All patients were found to be atopic (5 with allergic rhinitis); all had positive skin prick tests to mugwort (Artemisia vulgaris) pollen and other aeroallergens (for instance, pollen of plants from the genera Parietaria and Olea), and 5 had positive skin prick tests to hazelnuts, walnuts, and peanuts. Mustard sensitivity (cross-reactivity with cabbage) was detected in all patients. Patients demonstrated no allergic reaction to cooked cabbage. All patients were found to have cabbage-specific IgE antibodies in their sera [23]. 


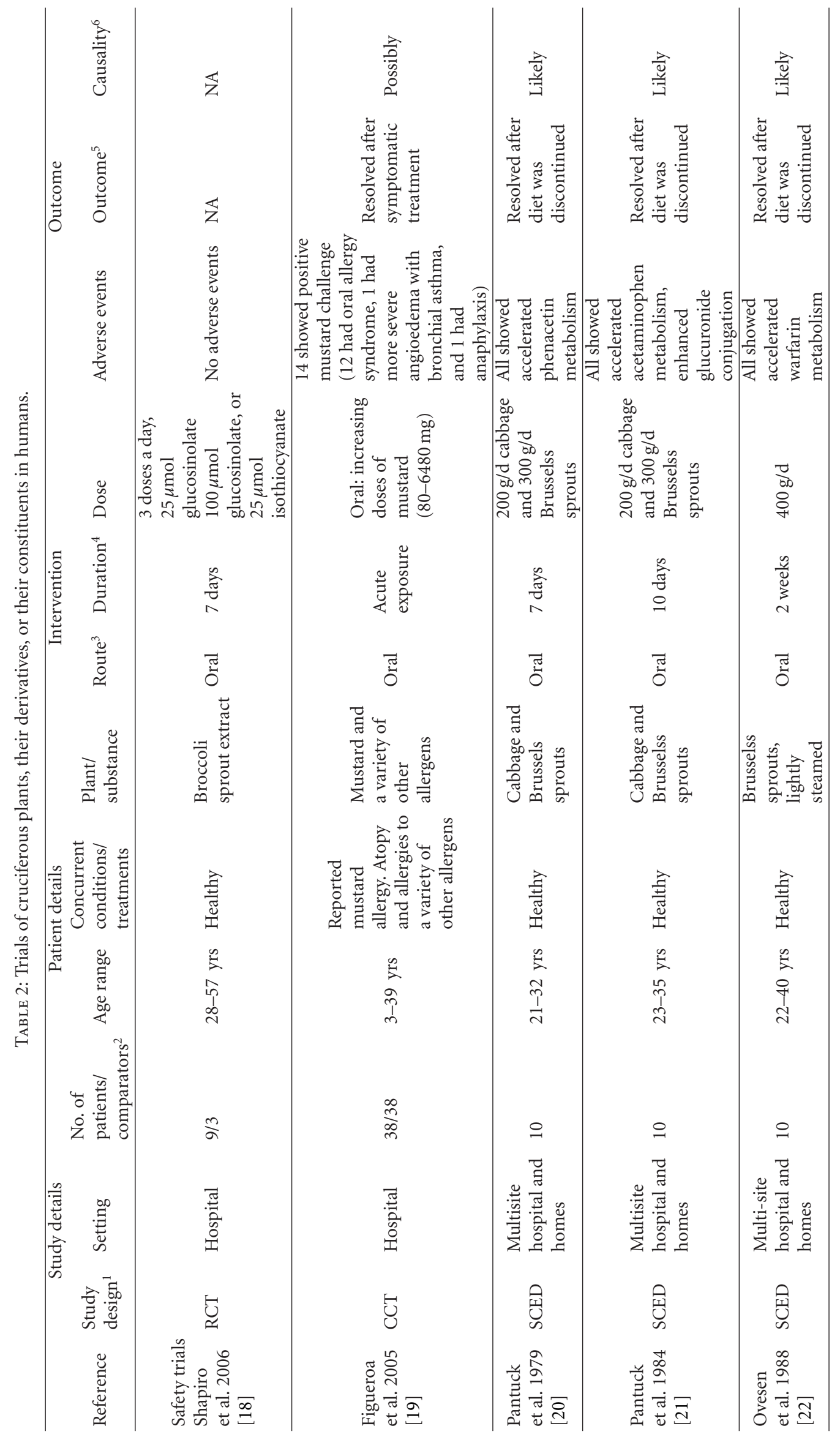




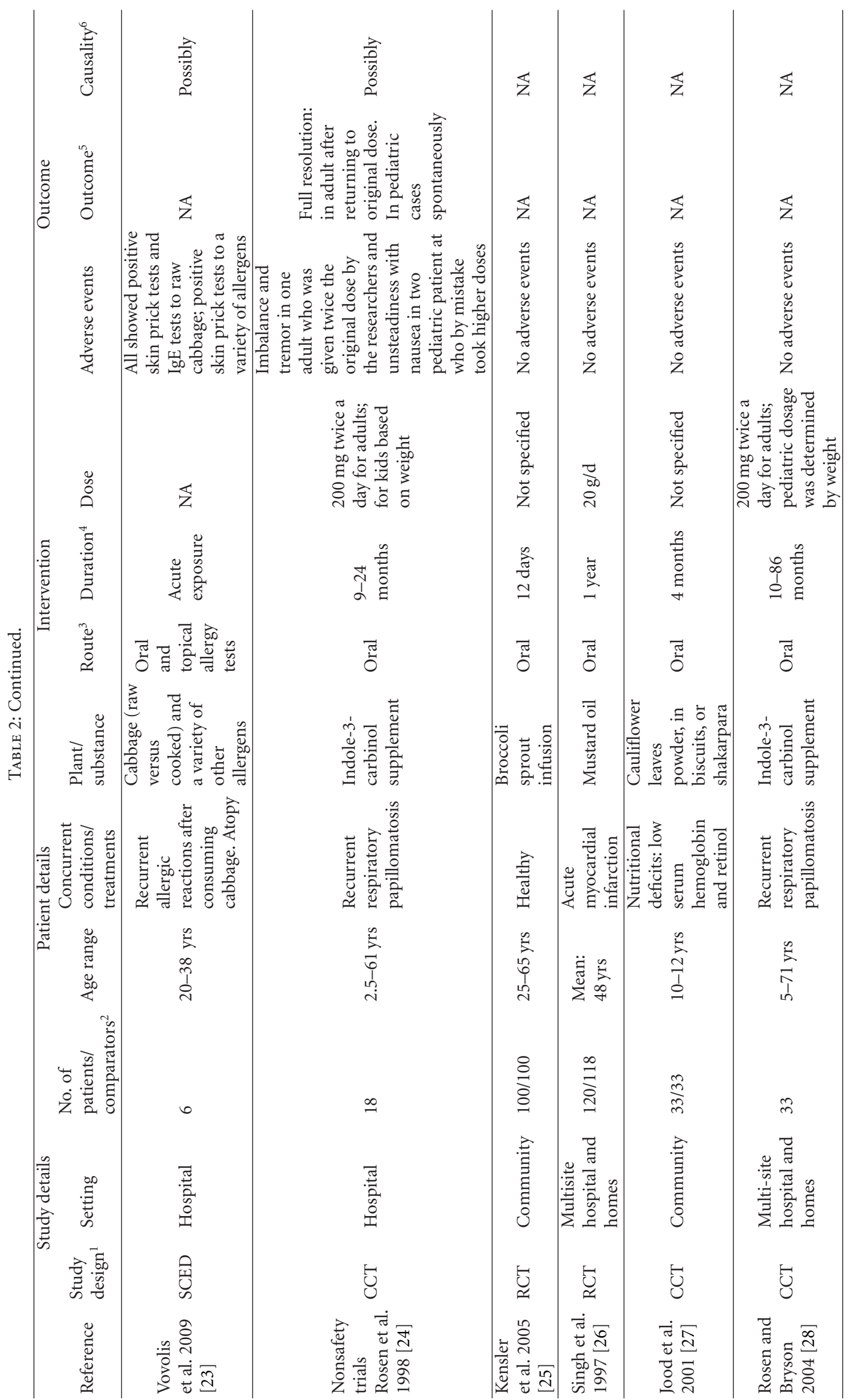




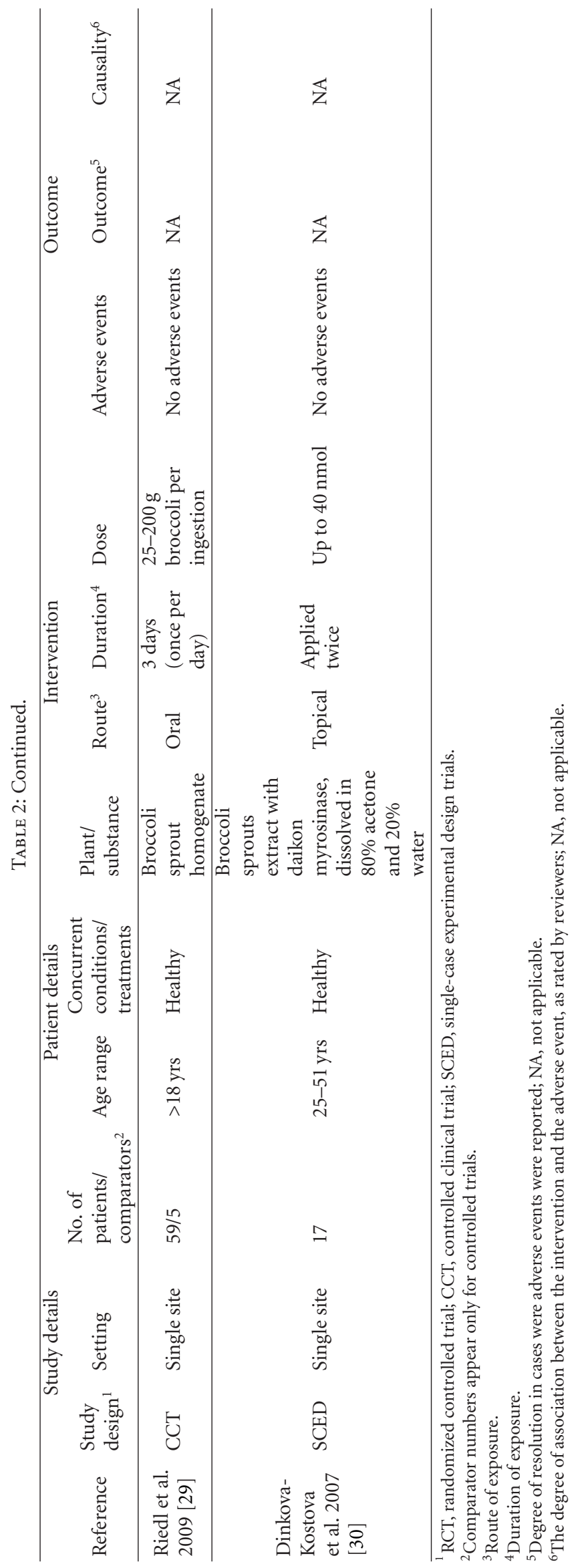


The nonsafety trials [24-30] included 2 RCTs, 4 controlled clinical trials, and 1 single-case experimental design trial, of which only one identified adverse events.

The trial which reported the adverse events was a controlled clinical trial in 18 subjects, ages 2.5-61, who suffered from recurrent respiratory papillomatosis and underwent complete surgical removal. All subjects received oral indole3-carbinol supplementation for a period of 9-24 months in order to examine whether the supplements reduced the occurrence of the papillomas. Doses were $200 \mathrm{mg}$ twice a day for adults, and individually calculated for pediatric patients based on body weight. Adverse events were reported in 3 patients: 1 adult, who was receiving a higher dose $(400 \mathrm{mg}$ twice a day) for 10 days according to the researchers' recommendation, suffered from imbalance and tremor and 2 girls, 2.5 and 12 years old, who took an overdose by mistake, suffered from unsteadiness and nausea. The symptoms in the adult resolved after returning to original dose and resolved spontaneously in the girls within a few hours to a day. According to the authors, the supplement did not cause any other side effects or complications (including acceleration of the disease) and was generally well tolerated [24]. It is unclear from this paper which other medications these specific individuals were taking, and whether they had any other acute health conditions which may have contributed to the adverse events described.

All other non-safety trials reported no adverse events with oral consumption of broccoli sprout infusion/homogenate, mustard oil, cauliflower leaves powder or indole-3carbinol supplements, or with topical application of broccoli sprouts extract [25-30]. These studies included both adult and pediatric populations, whose concurrent medical conditions included none (healthy), nutritional deficits (haemoglobin and retinol), recurrent respiratory papillomatosis, and acute myocardial infarction (Table 2).

3.3. Observational Studies. Thirteen observational studies were included, reporting adverse events related to cruciferous plants in 1,247 patients [31-43]. Seven of them were cohort studies, 3 were case-control studies, 2 were cross-sectional studies, and 1 was a qualitative survey (Table 3 ).

Three cohort studies, one case-control study, and one cross-sectional survey examined prevalence of allergic reactions to oilseed rape [31-35]. In the first cohort, 7/1478 subjects who were naturally exposed to oilseed rape had either a positive skin test, a positive radio-allergosorbent test, or nasal sensitivity in response to oilseed rape exposure, whereas the proportion of such allergic reactions was 14/37 in those who were occupationally exposed to oilseed rape [31].

In the second cohort, only 147/4468 subjects with suspected oilseed allergy showed positive skin prick test to oilseed rape; most of the subjects in this study were allergic to a variety of other antigens [32].

In the third cohort, $12 / 22$ village residents reported increased allergic symptoms during a year when oilseed rape surrounded the village, compared with a year when another crop surrounded the village. However, authors mention that the symptoms reported did not correlate with oilseed rape pollen levels measured. They were therefore not sure what the true cause could be [33].

In a case-control study, 37 people complained of seasonal allergic symptoms and bronchial reactivity in response to an unknown allergen, of whom 23 were tested. However, only 2 were found to be allergic to oilseed rape and only 10 (including those 2) were found to be atopic. The authors concluded that the symptoms could not be attributed to oilseed rape in most of these cases of seasonal allergy [34].

In the cross-sectional survey, 683/869 of village residents who were exposed to oilseed rape complained of seasonal cough, wheeze, and headaches. However, the authors concluded that the proportion of people who suffered from such symptoms was not much higher in subjects living in close proximity to oilseed rape in comparison to control subjects who do not; this suggests that the seasonal symptoms in rural areas cannot be attributed to oilseed rape allergy alone [35].

Yet another observational study dealing with allergic reactions was a cohort in 259 individuals with suspected contact allergy to foods containing allyl-isothiocyanate. Of 259 subjects who underwent allergy skin tests, 43 had a questionable reaction, of whom 15 had irritation and 3 had follicular reaction. Only two showed a true positive reaction, but one was lost to followup [36].

Three studies suggested a possible connection between cruciferous vegetables and cancer. The first was a cohort study in 64,327 women in Japan, ages 40-79, which examined the possible connection between dietary habits and risk of ovarian cancer death, based on food-frequency questionnaires. Whereas no adverse events were reported with consumption of cabbage or green leafy vegetables, a positive association was established between moderate-high consumption of Chinese cabbage and ovarian cancer. The authors suggest that this might be attributed to the fact, that, in many cases, Chinese cabbage is eaten pickled, as pickled food was proven to increase the risk of cancer [37]. The researchers did not adjust for total energy consumption, or for comalignancies such as breast/endometrial cancer; the first is important as several studies found an association between total energy consumption and increased risk for various types of cancer $[38,39]$. The latter is crucial, as many women with a history of such comalignancies are at a higher risk of developing ovarian cancer than the general population $[40,41]$.

The second suggested a connection between cruciferous vegetables and cancer in a case-control study from Kuwait in which 313 thyroid cancer patients were paired with age- and gender-matched controls; the study's aim was to examine the relationship between different sociodemographic, medical or dietary factors and thyroid cancer, based on questionnaires. Whereas no adverse events were associated with broccoli consumption, a nonstatistically significant positive association was established between moderate-high consumption of cauliflower or cabbage and thyroid cancer $(P=0.08$ and $P=$ 0.16 , resp.). The authors conclude that no clear association between consumption of cruciferous vegetables and thyroid cancer could be established [42].

The last study bringing up a possible association between cruciferous vegetable consumption and cancer is a case-control study which paired 246 thyroid cancer patients from 


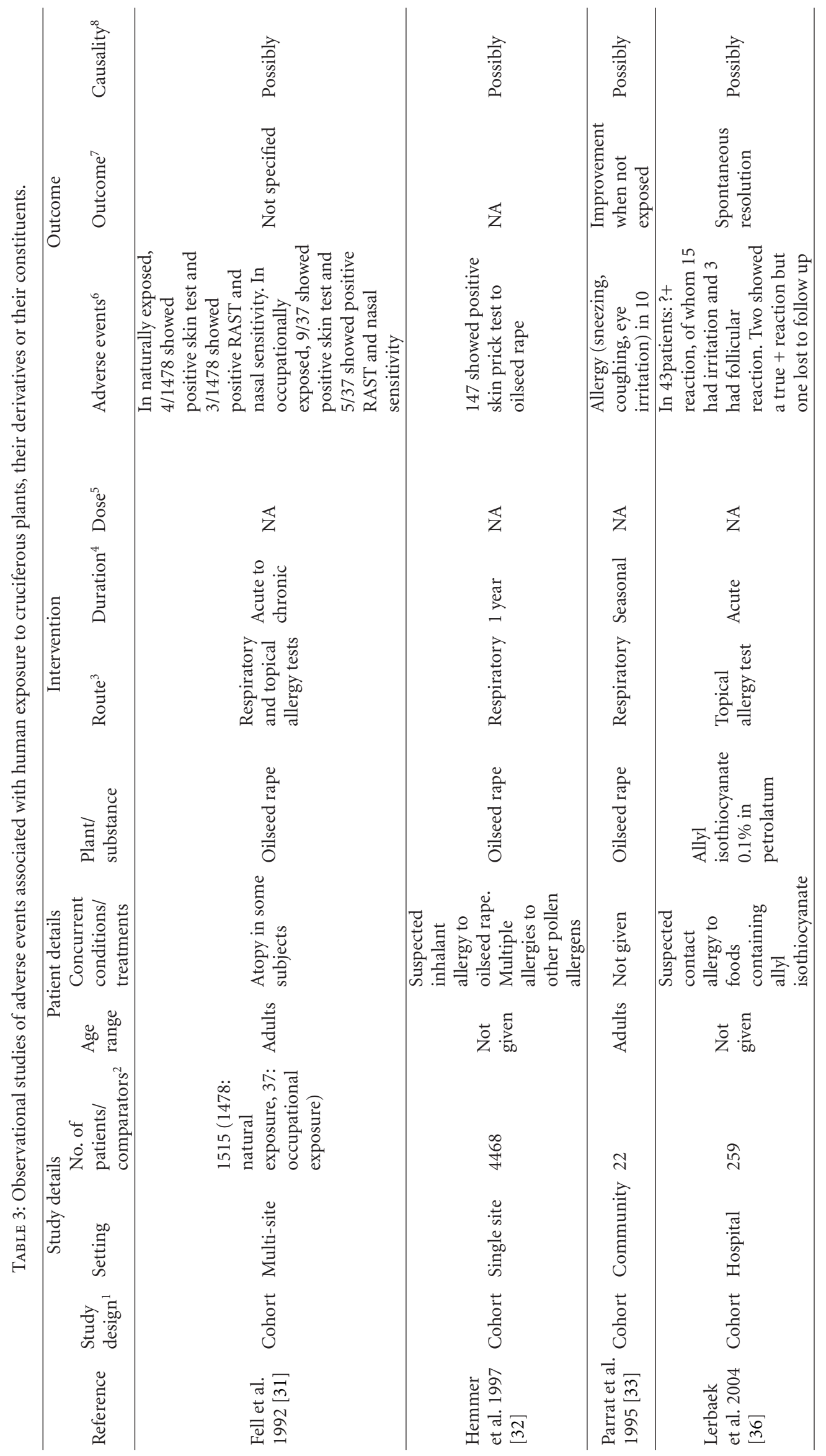




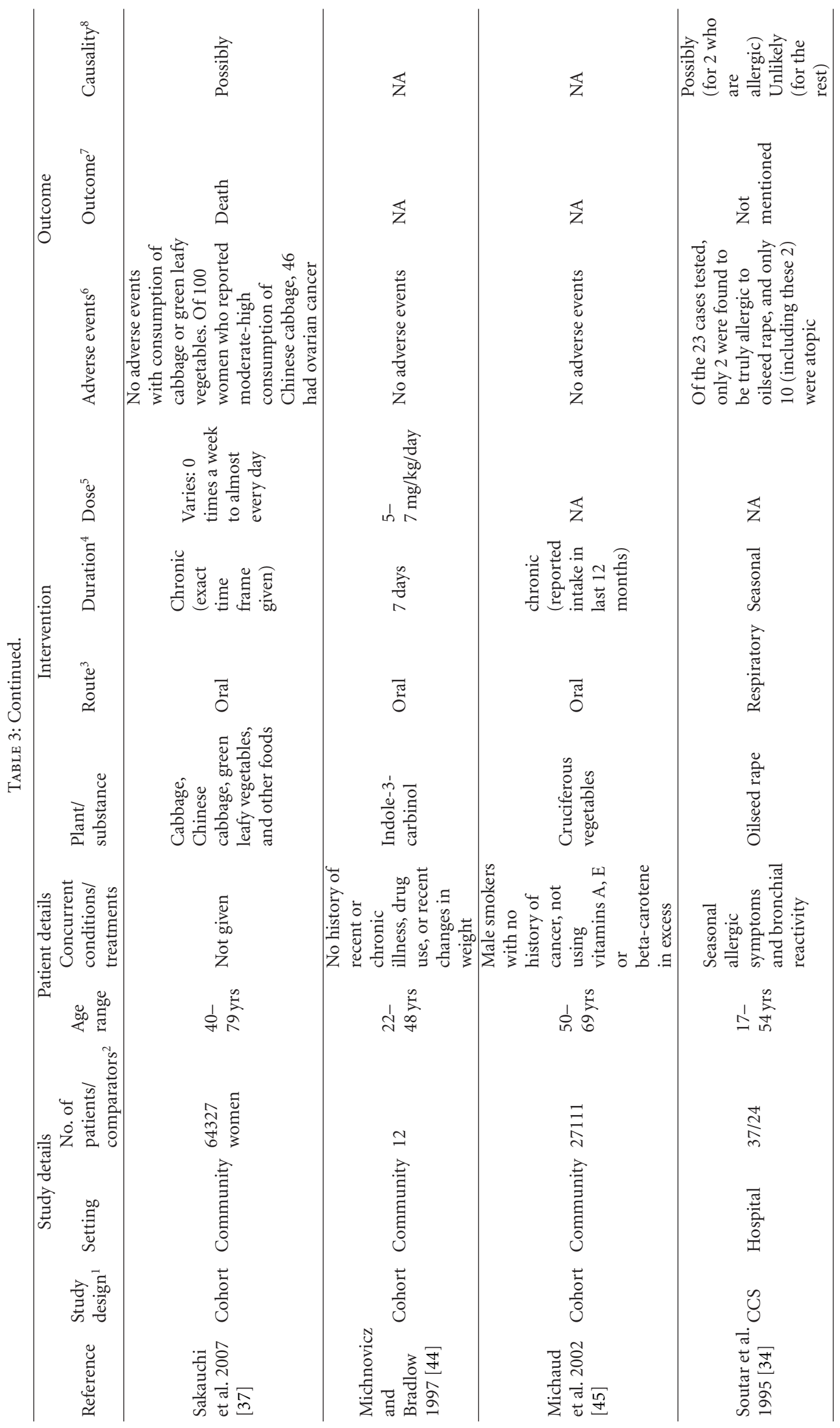




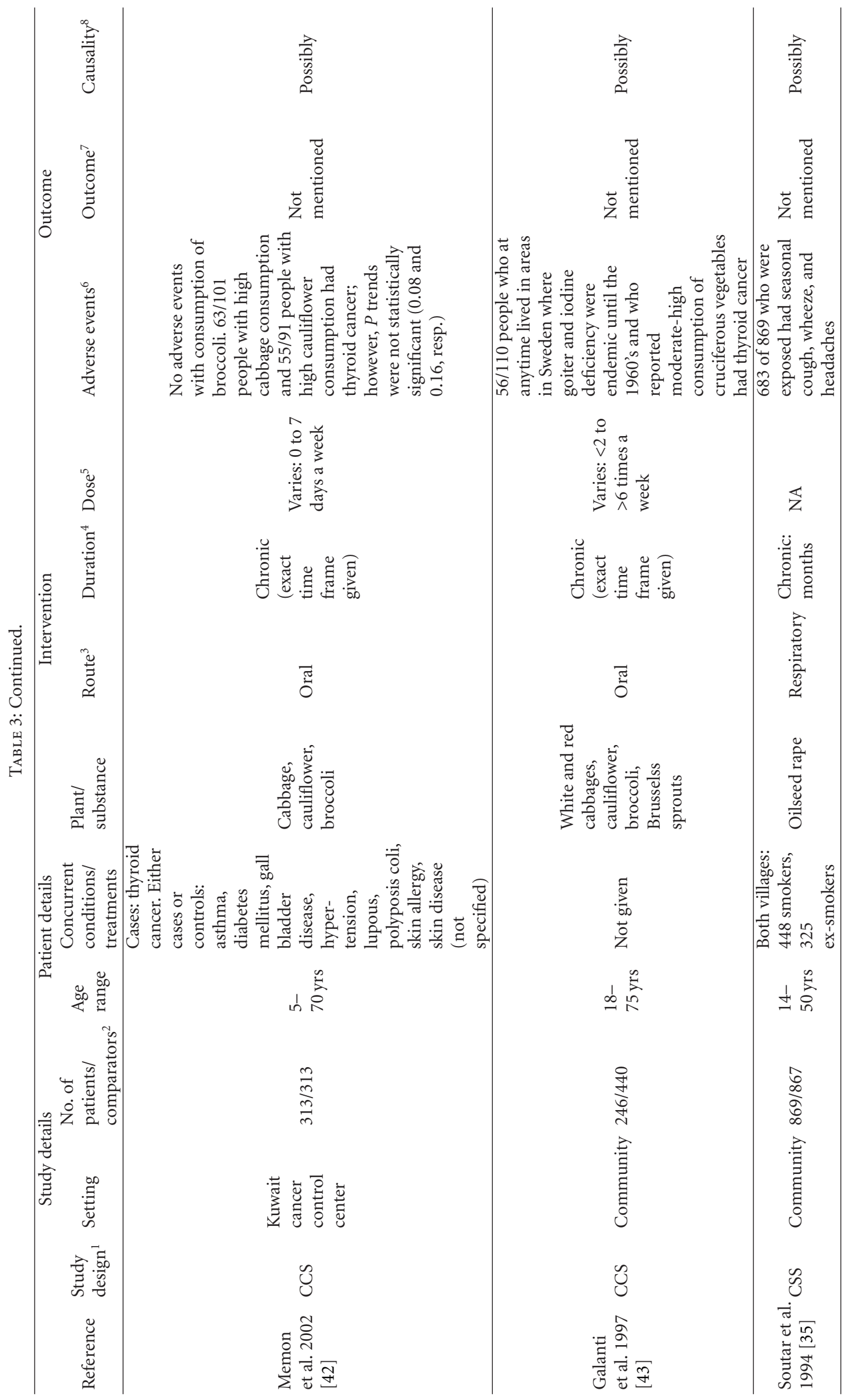




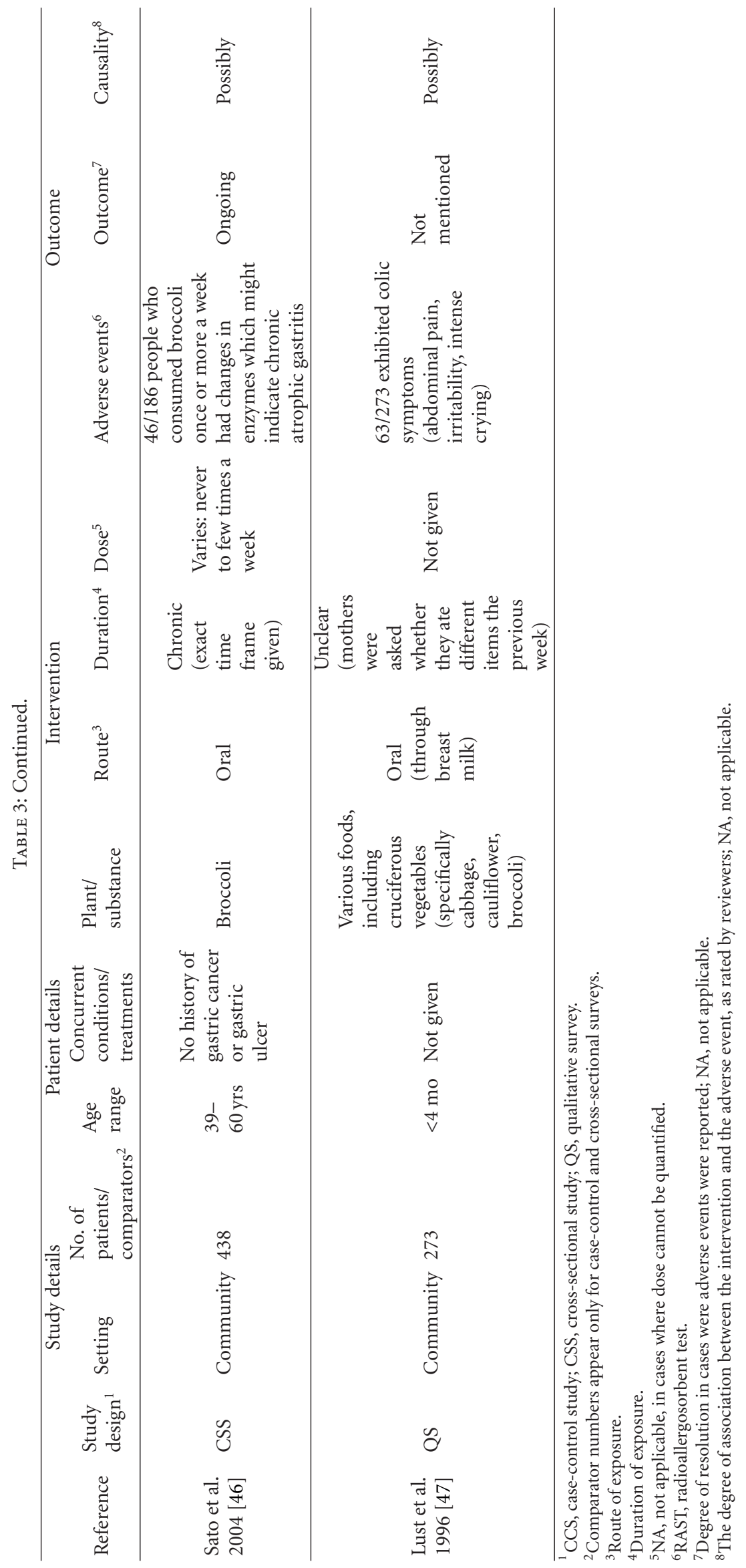


Sweden and Norway with 440 age- and gender-matched controls. The goal of the study was to evaluate the relationship between certain dietary habits and the risk of follicular and papillary thyroid carcinomas. With regard to cruciferous vegetables, researchers found that for people who, at any time, resided in areas of Sweden where goiter and iodine deficiency were endemic until the 1960's, there was an increased risk for thyroid cancer with consumption of cruciferous vegetables. These findings were not reproduced anywhere else in Sweden or Norway. Authors suggest that this dual effect might be related to interactions between cruciferous vegetables and other food components such as iodine [43]. They also expressed surprise, as their findings stood in contradiction to those of many research groups that found a protective effect of cruciferous vegetables against thyroid cancer [48-51].

The next observational study included in our paper was a cross-sectional study which aimed to determine the association between broccoli consumption and chronic atrophic gastritis in 438 men, ages 39-60 years. The authors found that consumption of broccoli once or more weekly increased the risk for chronic atrophic gastritis, based on serological tests for pepsinogen I and II. However, the authors acknowledge some major drawbacks to their work. First, H. Pylori infection, which increases the risk for chronic atrophic gastritis, was not measured. Second, serologic criteria were used for diagnosis, meaning that the results were prone to measurement errors. Moreover, it is unclear whether the changes in enzyme profiles were accompanied by any clinical manifestations [46].

The last observational study reporting adverse events was a qualitative survey which examined the relationship between consumption of certain foods by breast-feeding mothers, and the appearance of colic symptoms in their babies (4 months old or younger). The survey conductors found a positive association between consumption of cruciferous vegetables (cabbage, cauliflower, and broccoli) and colic symptoms: abdominal pain, irritability, and intense crying [47]. This study exhibited several major limitations: first, all determinants of colic symptoms, as defined by the authors (intense crying, irritability, and abdominal pain) can be subjected to subjective interpretation; the diagnosis of infantile colic, as established over 50 years ago, requires a healthy baby to exhibit "periods of intense, unexplained fussing/crying lasting more than 3 hours a day, more than 3 days a week for more than 3 weeks" [52]. In the study, however, no such objective temporal requirements were defined; any presentation of the symptoms, regardless of duration, was considered to constitute colic. Furthermore, since the questionnaire was administered over the course of one week only, instead of the 3 weeks which are required for diagnosis of colic, it is doubtful whether such diagnosis can be made at all. Moreover, since food intake and colic symptoms were reported only for a week, it is hard to establish proper temporal relationships between the two.

Two cohort studies included in our paper identified no adverse events with exposure to cruciferous plants or their constituents; the first study included 12 subjects who ingested $5-7 \mathrm{mg} / \mathrm{kg} /$ day of indole-3-carbinol [44]. The second study, which followed 27,111 male smokers over a period of
12 months, attempted to discover whether intakes of fruits, vegetables, carotenoids, or vitamins $\mathrm{A}, \mathrm{E}$, or $\mathrm{C}$ could be associated with risk of bladder cancer in these people. The study determined that no association between bladder cancer risk and chronic consumption of cruciferous vegetables could be established [45].

3.4. Case Reports. Twenty-four case reports were included in the review, reporting adverse events in 35 individuals. The patients ranged from 17 to 70 years of age, whose concurrent medical conditions included allergies, both to cruciferous plants and to a variety of other allergens, asthma, bronchitis, atopy, cardiovascular diseases, and different skin conditions (eczema, pruritus, eryhtema, dermatitis, dryness and scaling, and blisters) (Table 4). The adverse events occurred after topical, respiratory, or oral exposure to different cruciferous plants, their constituents, or their derivatives. Twenty-one case reports reported allergic or hypersensitivity reactions in 31 individuals, including allergic contact dermatitis/contact urticaria, contact hypersensitivity, aggravation of eczema, cutaneous lesions similar to pityriasis rosea, asthma, rhinoconjunctivitis, aggravation of cough and chest pain, local swelling and itching, and anaphylaxis. The suspected agents triggering these reactions were turnip seeds, cabbage, broccoli, oilseed rape (flour or pollen), cauliflower, mustard (a variety of preparation forms), isothiocyanates in paint, and Diplotaxis erucoides (Brassica erucoides) pollen. It is important to note that 18 of the individuals (approximately $50 \%$ of total) had previous risk factors such as atopy, allergies to allergens unrelated to cruciferous plants (for instance, grasses, dust mite, nuts), different skin conditions, or asthma. Furthermore, 12 of those people had been exposed to the allergens occupationally, for chronic periods of time, presumably leading to the adverse events [53-73].

Two case reports documented warfarin resistance in 3 patients with cardiovascular diseases. The first patient had a prosthetic aortic valve and a history of myocardial infarctions with prolonged prothrombin time [74]. The second had pulmonary embolism, and the third suffered from an unspecified cardiovascular disease [75]. The adverse event in the first patient was attributed to excessive consumption of lettuce and greens (turnip, mustard greens, broccoli); the patient was a 35 years old woman who intended to lose weight by consuming only the above-mentioned foods, which led to a consumption of $6000 \mu \mathrm{g} /$ day of vitamin K (60 times higher than the recommended consumption). After 5 weeks of dieting, she felt substernal chest pain and was referred to the hospital, where a myocardial infarction was diagnosed. She was treated with heparin and nitroglycerine. The second and third cases were attributed to chronic consumption of up to $450 \mathrm{~g} /$ day of broccoli; one of them required treatment with Coumadin. All three cases ended up in full resolution of adverse events and a recommendation to restrict consumption of vitamin K-rich foods [74, 75].

The last case report reported a suspected toxic irritative dermatitis (nonallergic) in an individual who applied a home-made mustard wrap in order to relieve the symptoms of bronchitis; authors believe the wrap may have contained some toxic compounds and concluded that the reaction was 


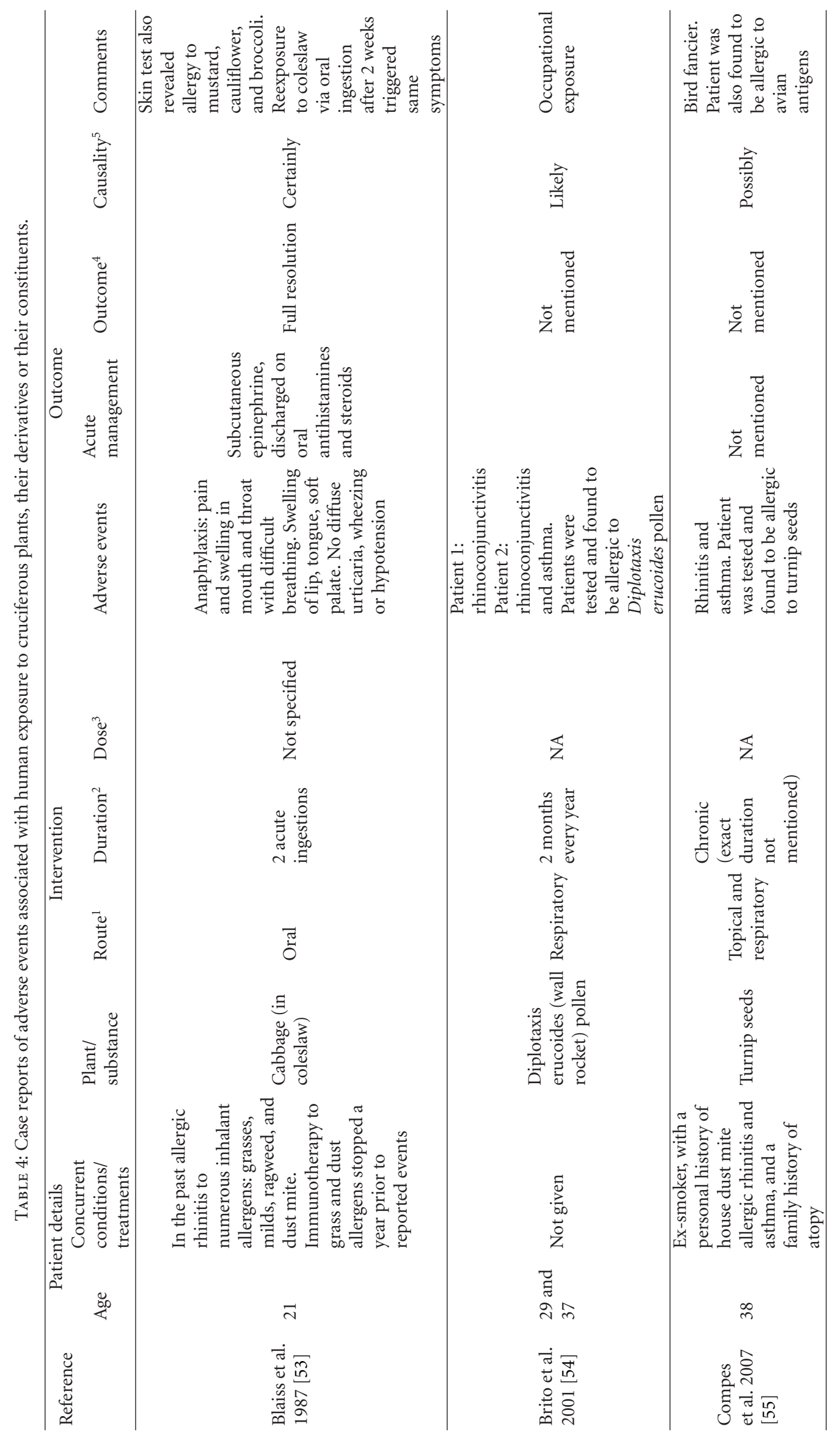




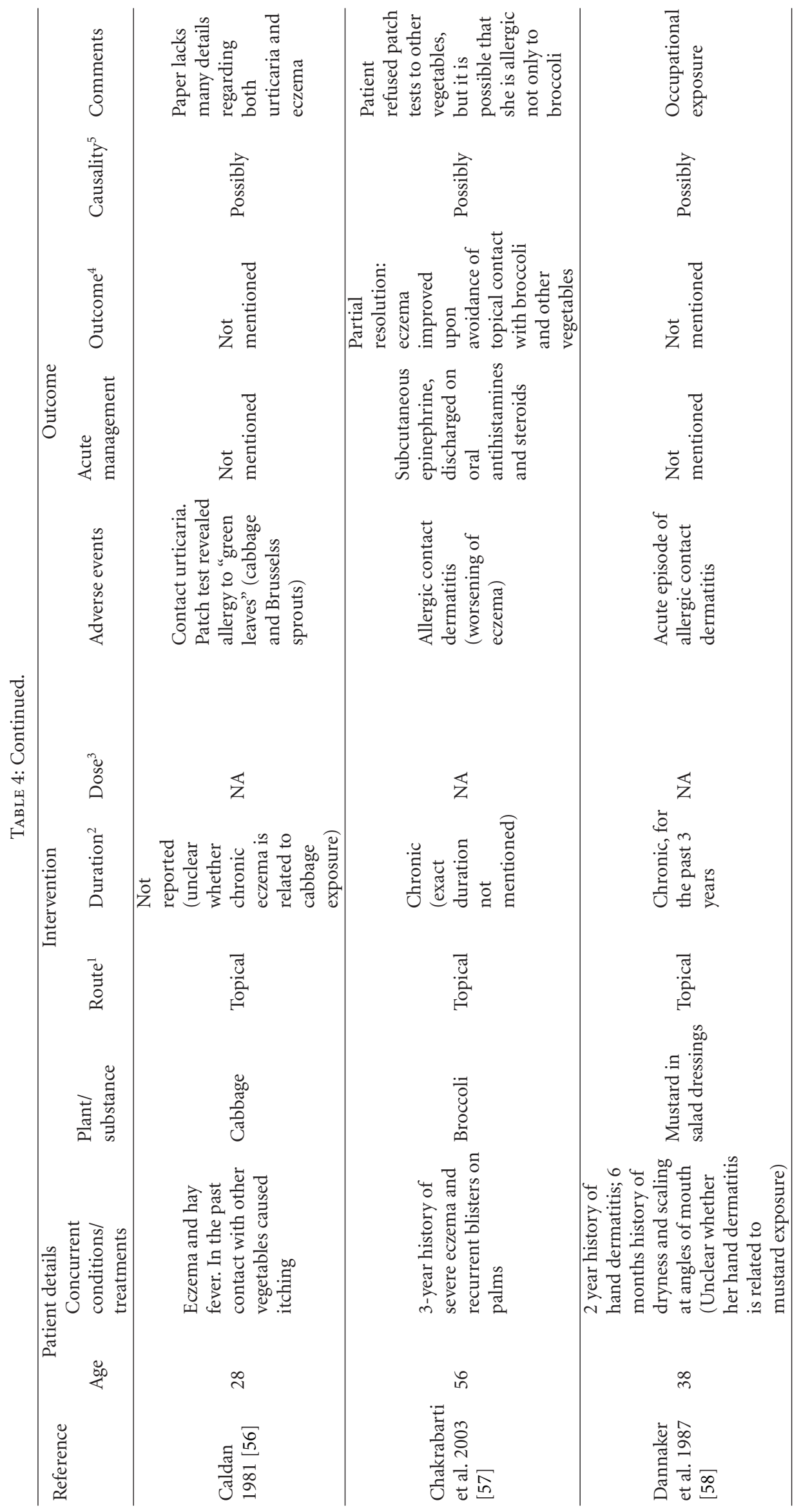




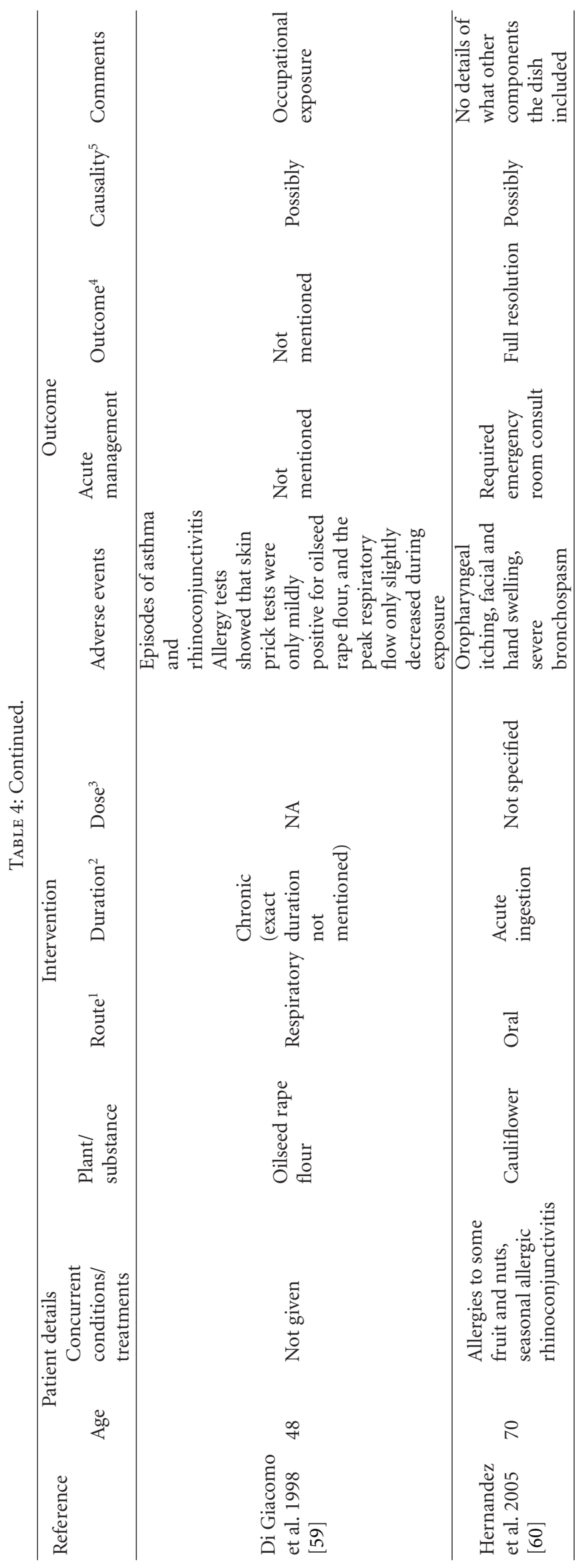




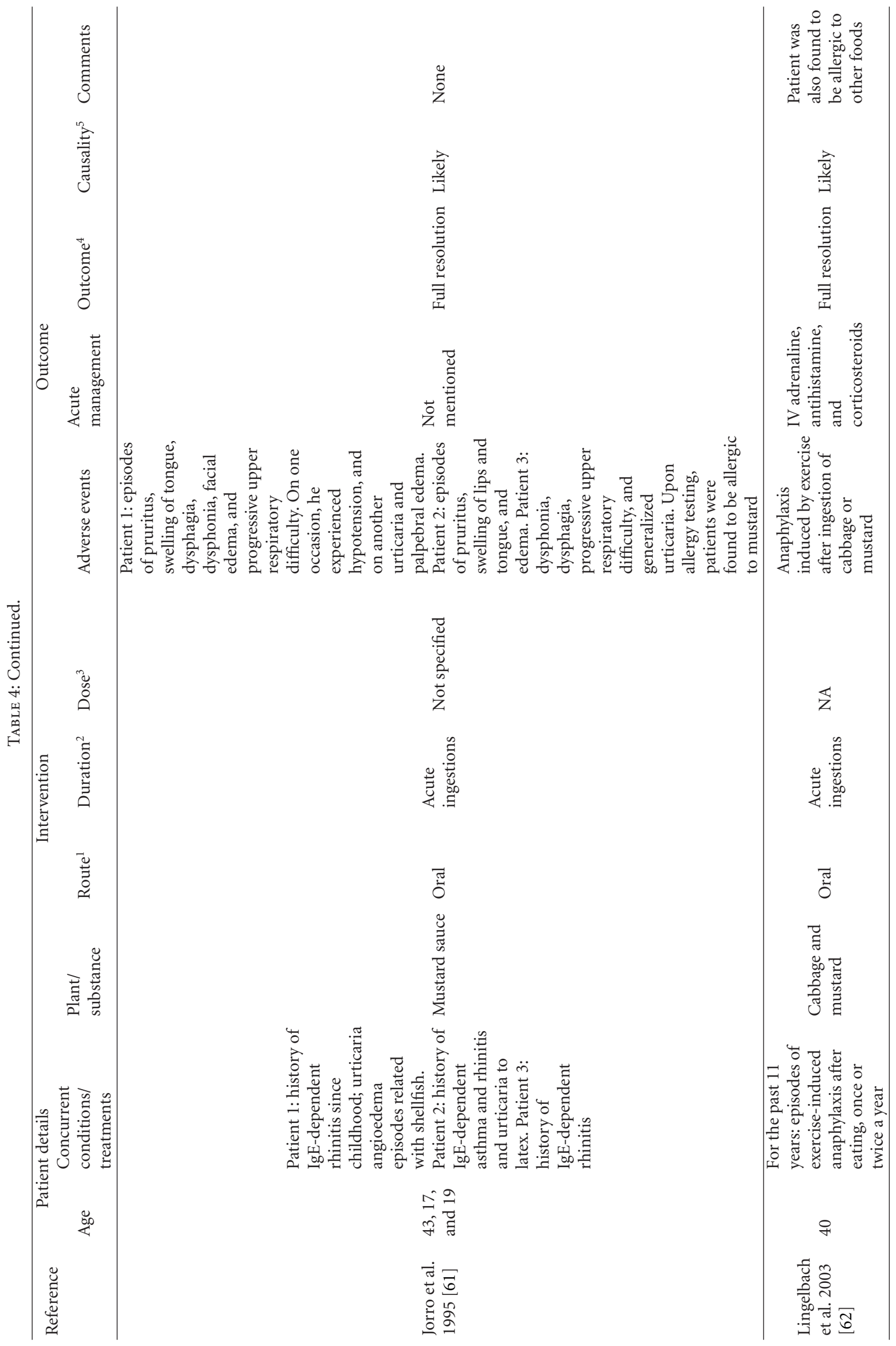




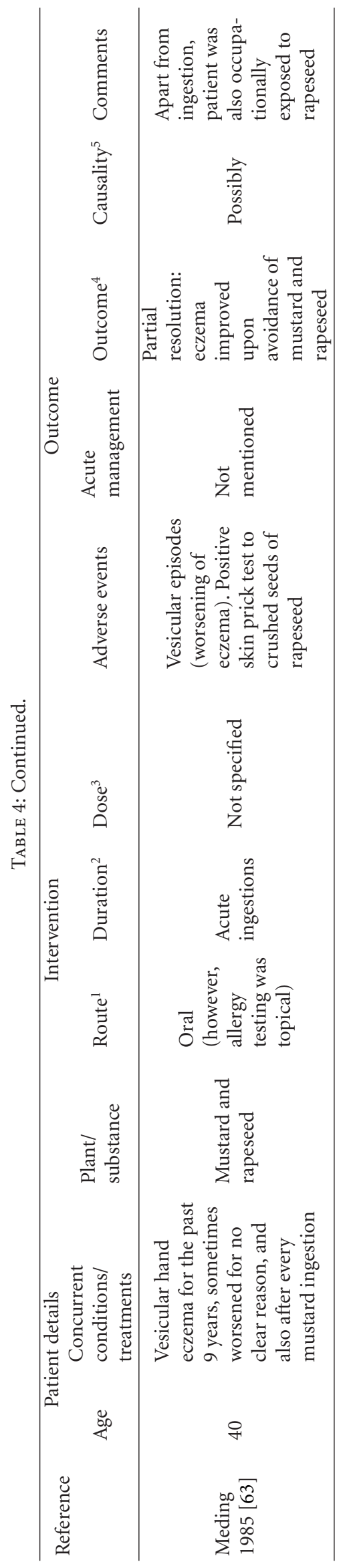




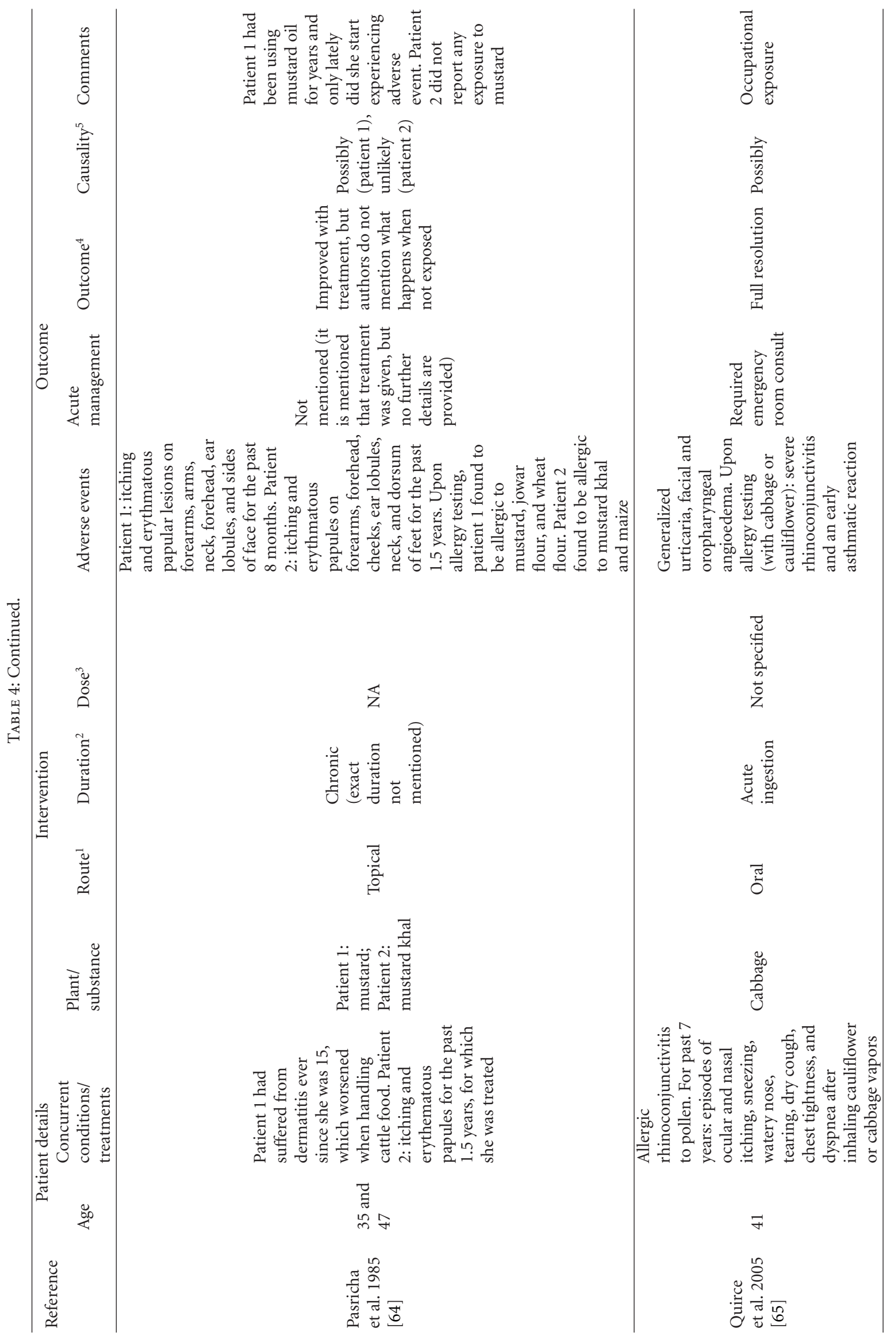




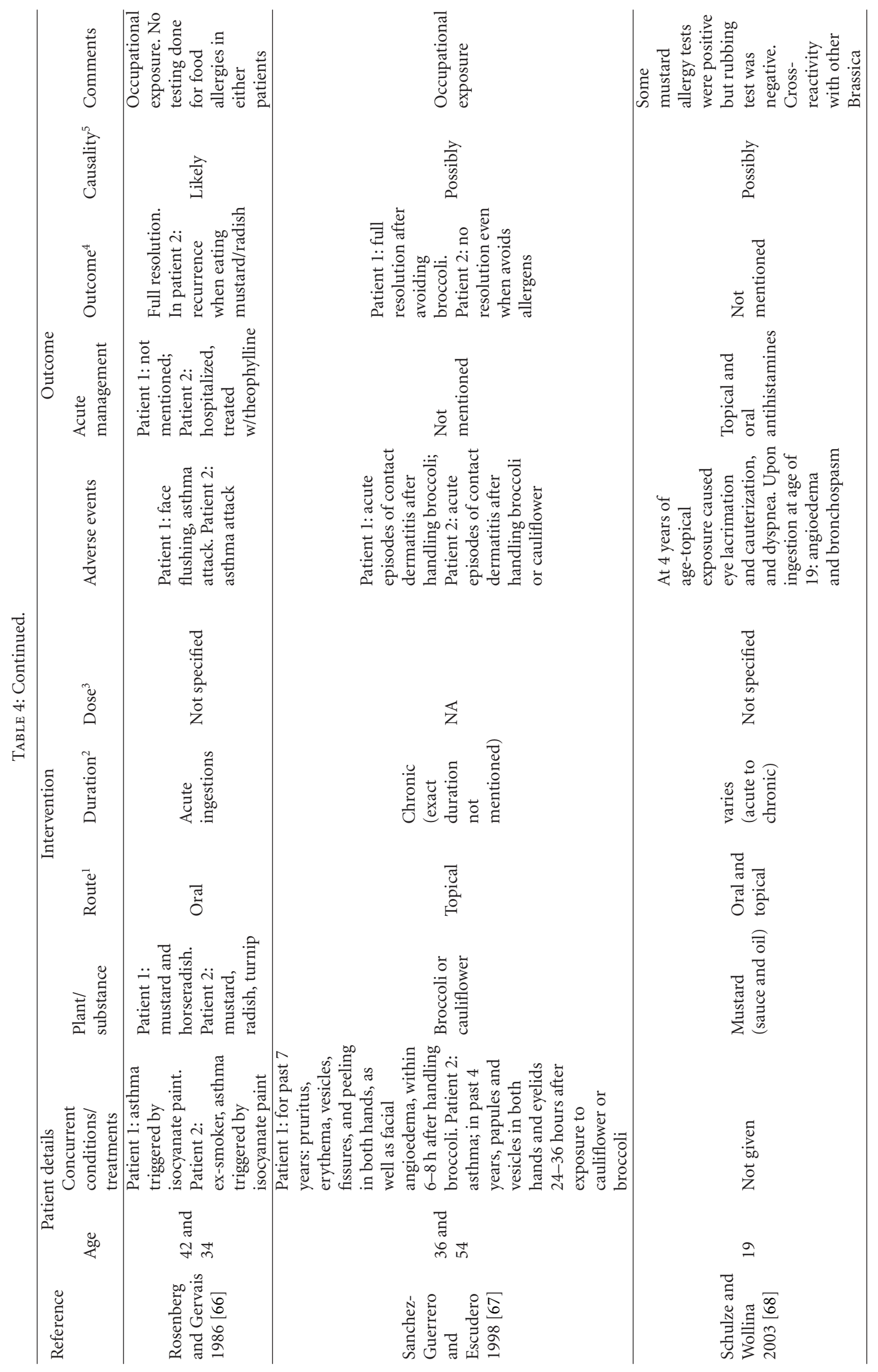




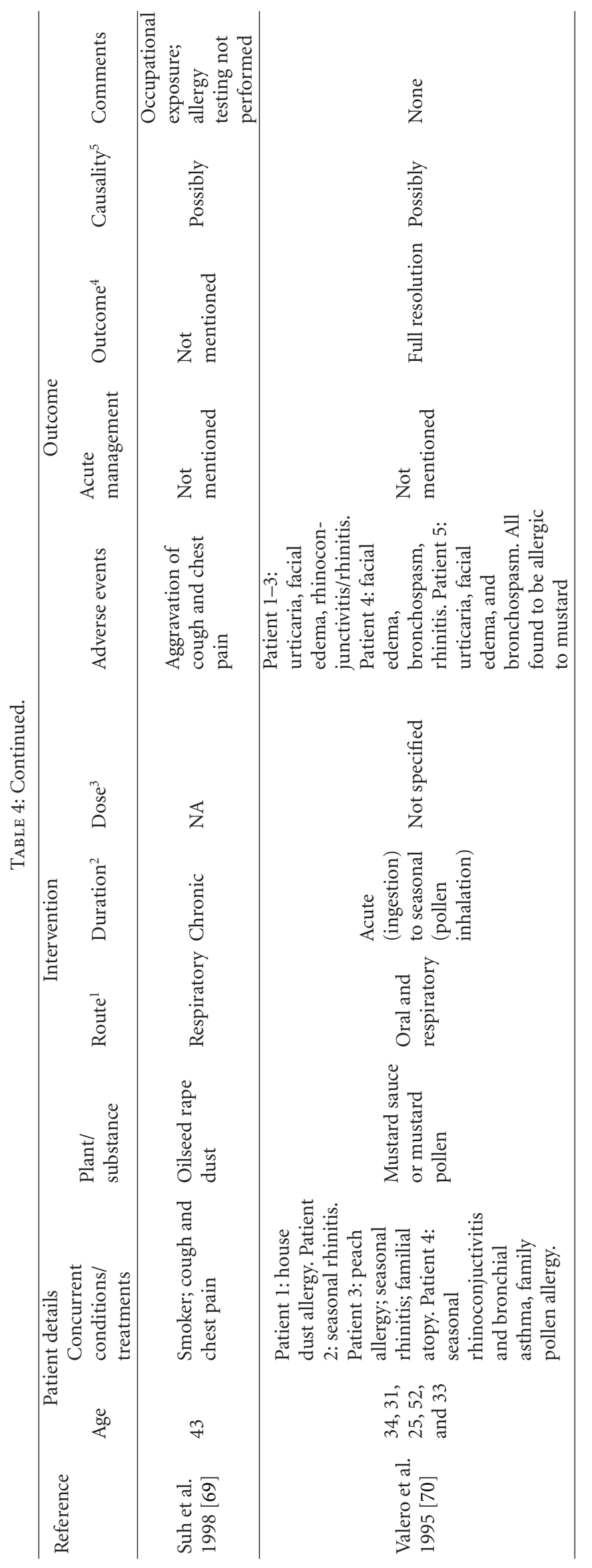




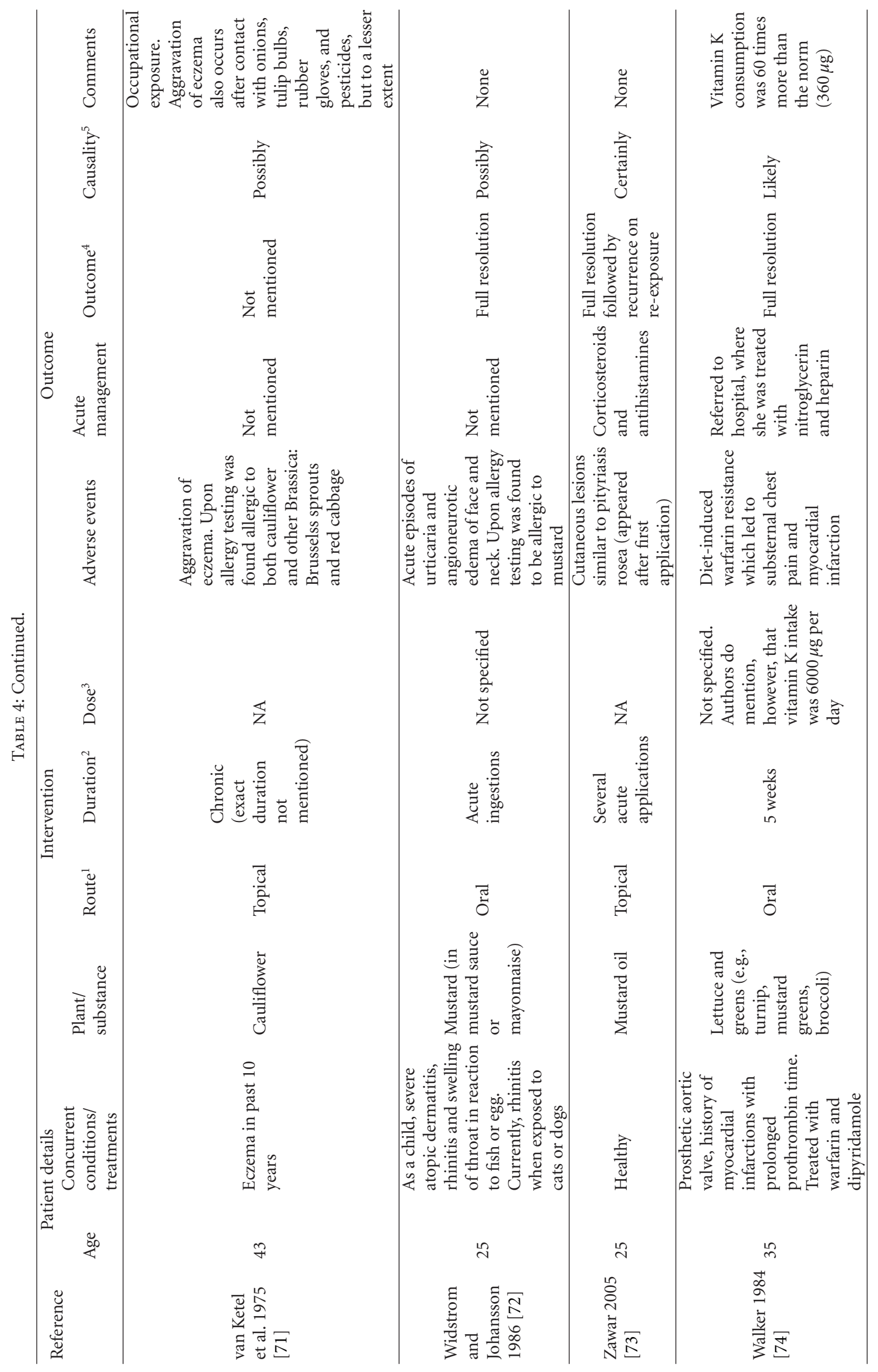




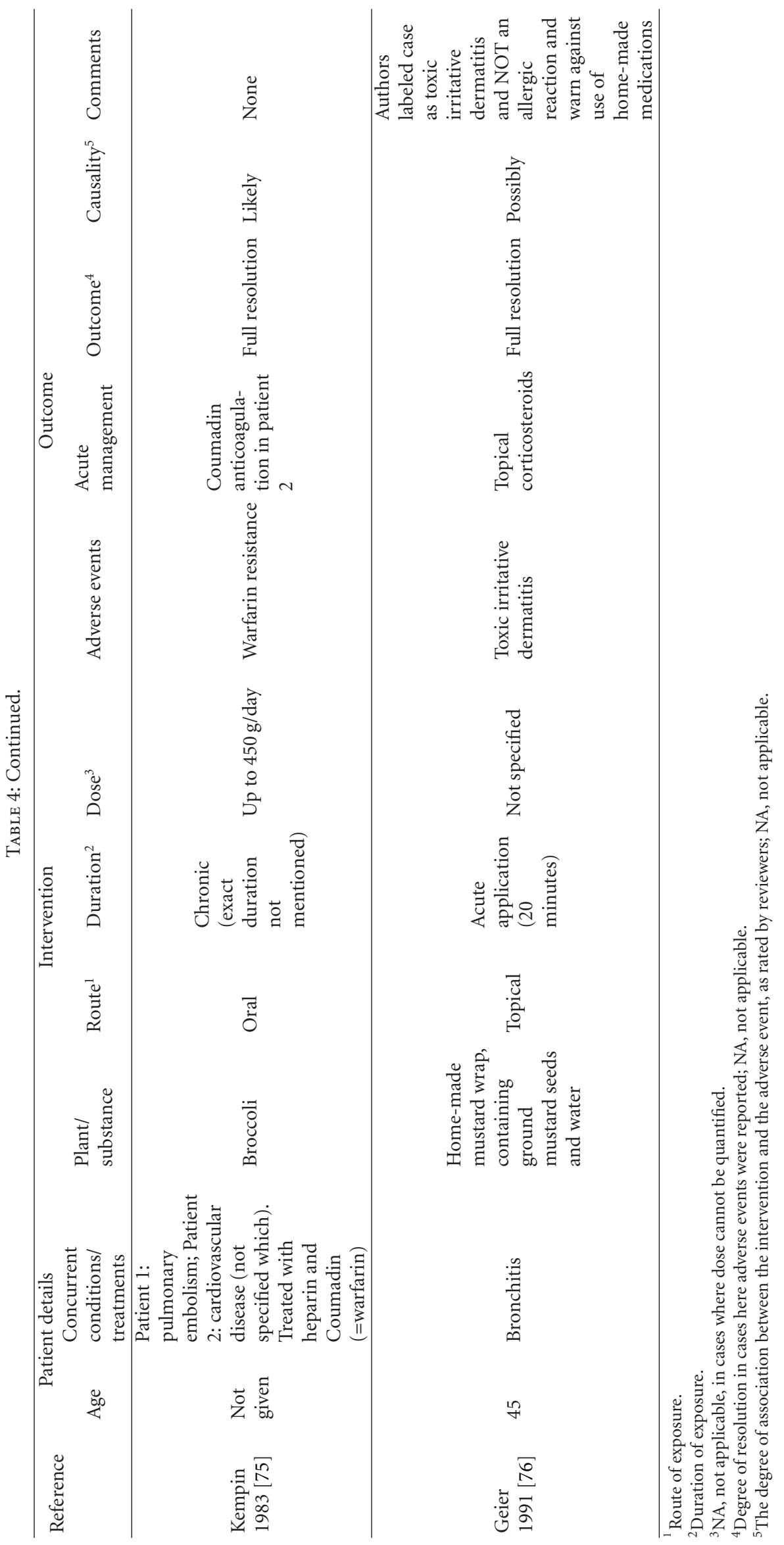


not an allergic one. Hence, they advised against the use of home-made wraps. The patient was treated with corticosteroids with full resolution. This case was very brief and lacked a great deal of information regarding previous medical history and whether other medications had been used to treat the patient's bronchitis. Moreover, no test was conducted to verify the cause of the adverse event [76].

3.5. Excluded Papers. Of the 317 papers excluded, $280 \mathrm{did}$ not fulfill the criteria for our systematic review (i.e., they did not evaluate adverse effects or lack thereof, intervention or substance exposure did not include cruciferous plants, or did not present original data). Another 37 articles were excluded since they dealt with toxic oil syndrome. In order to promote transparency in our decision-making process, we shall explain the rationale behind excluding this latter group of papers.

Toxic oil syndrome is the name given to a disease outbreak in Spain in 1981. Its first appearance was as an acute lung disease, which was followed by a range of other chronic symptoms affecting the lungs, the liver, the kidneys, the skin, the joints, the central nervous system, and the immune system [77-83]. The cause for the disease was traced to the consumption of cheap, refined, rapeseed oil that had been intended for industrial use rather than for human consumption. It was sold as "olive oil" and was therefore used for cooking. According to the World Health Organization, toxic compounds derived during the refinement process, used to remove the aniline and to denature oils intended for industrial use, were responsible for causing the disease. Hence, toxic oil syndrome has come to be considered a chemical incident, rather than a side effect associated with consumption of rapeseed oil, since consumption of non-industrial rapeseed oil does not cause the disease. In fact, the specific refinement process of the oil that caused the disease was so unique that experimental studies performed in a variety of laboratory animals have hitherto failed to reproduce the symptoms of human toxic oil syndrome [84].

\section{Discussion}

Research conducted in the last decade supports the notion that some cruciferous plants and their derivatives may serve to prevent or attenuate several medical conditions. To further this field of investigation, we conducted this systematic paper to determine the safety parameters surrounding the use of cruciferous plants. In this regard, our review identified adverse events in 1335 individuals, out of a total of 101,198 individuals who were included in all studies. Of these, 1292 adverse events were ranked as only possibly or unlikely to be caused by cruciferous plants. Only 43 were determined to have been certainly or likely caused by exposure to cruciferous plants. Adverse events, which could certainly or likely be attributed to members of the Brassica genus, included allergic reactions (including anaphylaxis), changes in metabolism of acetaminophen, phenacetin and warfarin, and warfarin resistance. Most adverse events reported in our paper were allergic or hypersensitivity reactions; however, their significance for the general healthy population is hard to infer, due to confounding medical histories or low causality ratings. Adverse events from both allergy trials and case reports were mostly in individuals who suffered from atopy, allergies to cruciferous plants and/or other allergens (for instance, grasses, ragweed, dust mite, pollen, dogs, cats and different fruit and nuts), asthma, or a variety of skin conditions such as eczema, pruritus, erythema, dermatitis, dryness and scaling, or blisters. A possible conclusion from these case reports, however, is that occupational exposure to Brassica plants may predispose to develop an allergy to these plants. With regards to observational studies which investigated allergies to cruciferous plants or their derivatives, all concluded that the cases could not be attributed to the suspected culprits.

A second category of adverse events included changes in metabolism of phenacetin, acetaminophen, and warfarin. While phenacetin has been banned for use by the FDA, acetaminophen and warfarin continue to be widely used. As such, it was important to understand if these changes in metabolism pose any risk to those who use these drugs. As for acetaminophen, the authors explain that the decreased levels of the cysteine conjugate of acetaminophen found in subjects' urine actually indicate decreased toxicity; thus, cruciferous plants may not pose any risk to individuals who consume acetaminophen. With regards to warfarin, however, the finding that cruciferous vegetables alter its metabolism might bear greater clinical relevance. It has been suggested that foods high in vitamin $\mathrm{K}$, such as cruciferous vegetables, may interact with warfarin and its anticoagulant activity. In all case reports describing warfarin resistance, the patients had consumed very large amounts of cruciferous vegetables (up to $450 \mathrm{~g} /$ day or the equivalent of $6000 \mu \mathrm{g}$ vitamin K/day), amounts not warranted for consumption by the general population. However, it is possible that lower doses would have some effects on anticoagulation as well. Similarly large amounts of cruciferous vegetables ( $400 \mathrm{~g} /$ day) were given to subjects in the SCED trial which examined changes in warfarin resistance. As many foods interact with warfarin, among which are mango, avocado, fish oil, soy milk, and foods high in vitamin $\mathrm{K}$ [84], it is imperative for physicians to discuss the consumption of such foods (including cruciferous vegetables) with their patients when starting treatment with anticoagulants.

Reports of other types of adverse events identified in our systematic review, including cancer, chronic atrophic gastritis, infantile colic, and toxicity-related events, could only be ranked as possibly or unlikely to be caused by exposure to cruciferous plants, as there was not enough evidence to establish a stronger causal relationship between the suspected culprits and the adverse events. Further research employing better methodology should be undertaken in order to establish whether positive association exists between consumption of Brassica vegetables and any of the above-mentioned adverse events.

Finally, a number of studies did not find any adverse events associated with consumption of cruciferous plants or their derivatives in subjects with a variety of health conditions, including history of myocardial infarction, nutritional deficits, or recurrent respiratory papillomatosis, or in healthy individuals. 
In summary, to date, adverse events presumably related to cruciferous plants have been reported in 1335 individuals, identified through 50 studies which included a total of 101,198 individuals. However, the number of those which were certainly/likely caused by Brassica plants (including allergic reactions, changes in drug metabolism, and warfarin resistance) was much lower: only 43 of all reported adverse events received such high causality rating. For comparison, the literature shows that the pooled prevalence of adverse drug reactions ranges from 4.2 to $6 \%$ [85]. This frequency, if applied to cruciferous plants, would translate into $4250-$ 6072 reports of adverse events out of the included 101,198 individuals, a value much higher than what was found in our current study.

When analysing our findings, one must bear in mind that the total number of individuals included in all studies comprises both those who were definitely exposed to Brassica plants and those who were presumptively exposed as the degree of exposure could not be ascertained in all cases. This might cause the frequency of occurrence of adverse events to appear lower than the actual value. On the other hand, our study also included case reports of individuals, all of whom were exposed, and reported adverse events. In this regard, the frequency of adverse events tends to be an overestimation, since individuals who are exposed, but do not experience an adverse event, are likely not to report. Hence, the inclusion of these case report, in which essentially all individuals exposed report adverse events, may serve to balance this underestimation. We advise the reader to treat the broad pooled frequency presented in the previous paragraph $(1335 / 101,198)$ as merely gross estimations of the actual frequency, as conducting a meta-analysis per se was deemed inappropriate given the heterogeneity of study parameters (subjects, interventions, clinical outcomes, and study designs).

We conclude that cruciferous plants are generally safe for human consumption and use. However, individuals with known allergies/hypersensitivities to a certain member of the Brassica genus, or those taking warfarin, should consult with their physician before consuming such vegetables. In the future, if cruciferous derivatives are to be investigated as potential therapeutic agents, we recommend that adverse events be monitored. As our findings reflect positively on the safety of Brassica plants in humans and evidence from the current experimental literature of their benefit in certain disease states, we would encourage further exploration of their potential use in the clinical setting. The use of brassica or similar food products may have the potential to provide a safer alternative for the treatment of disease in comparison to current pharmaceutical interventions.

\section{Conflict of Interests}

The authors declare no conflict of interests.

\section{Author Contribution}

JYY initiated the research question; OS, EGC, DA, SS, SV, and JYY designed research; OS, EGC, DA, and SS conducted research; DA and SS provided essential materials; OS and EGC, analyzed data; OS wrote the paper; OS, EGC and JYY had primary responsibility for final content. SV provided guidance on study design and interpretation, including paper revisions. All authors read and approved the final paper.

\section{Acknowledgments}

This work was supported by grants from the Alva Foundation, the Heart and Stroke Foundation of Alberta, NWT and Nunavut, and NeuroDevNet, a Canadian National Centres of Excellence Grant. The authors would like to thank Ms. Miriam Schiffgen for translation of papers from German to English.

\section{References}

[1] E. Goldman, "Practical strategies for implementing integrative medicine in a primary care setting," Journal of Medical Practice Management, vol. 24, no. 2, pp. 97-101, 2008.

[2] S. Prakash and K. Hinata, Taxonomy, Cytogenetics, and Origin of Crop Brassicas: A Review, Swedish Natural Science Research Council, Stockholm, Sweden, 1980.

[3] S. Y. Kim, S. Yoon, S. M. Kwon, K. S. Park, and Y. C. LeeKim, "Kale Juice improves coronary artery disease risk factors in hypercholesterolemic men," Biomedical and Environmental Sciences, vol. 21, no. 2, pp. 91-97, 2008.

[4] A. Yanaka, J. W. Fahey, A. Fukumoto et al., "Dietary sulforaphane-rich broccoli sprouts reduce colonization and attenuate gastritis in Helicobacter pylori-infected mice and humans," Cancer Prevention Research, vol. 2, no. 4, pp. 353-360, 2009.

[5] P. Brennan, C. C. Hsu, N. Moullan et al., "Effect of cruciferous vegetables on lung cancer in patients stratified by genetic status: a mendelian randomisation approach," The Lancet, vol. 366, no. 9496, pp. 1558-1560, 2005.

[6] P. H. Chyou, A. M. Y. Nomura, J. H. Hankin, and G. M. Stemmermann, "A case-cohort study of diet and stomach cancer," Cancer Research, vol. 50, no. 23, pp. 7501-7504, 1990.

[7] M. Hara, T. Hanaoka, M. Kobayashi et al., "Cruciferous vegetables, mushrooms, and gastrointestinal cancer risks in a multicenter, hospital-based case-control study in Japan," Nutrition and Cancer, vol. 46, no. 2, pp. 138-147, 2003.

[8] L. I. Wang, E. L. Giovannucci, D. Hunter, D. Neuberg, L. Su, and D. C. Christiani, "Dietary intake of Cruciferous vegetables, Glutathione S-transferase (GST) polymorphisms and lung cancer risk in a Caucasian population," Cancer Causes and Control, vol. 15, no. 10, pp. 977-985, 2004.

[9] J. M. Pogoda, S. Preston-Martin, G. Howe et al., "An international case-control study of maternal diet during pregnancy and childhood brain tumor risk: a histology-specific analysis by food group," Annals of Epidemiology, vol. 19, no. 3, pp. 148160, 2009.

[10] M. H. Noyan-Ashraf, L. Wu, R. Wang, and B. H. J. Juurlink, "Dietary approaches to positively influence fetal determinants of adult health," The FASEB Journal, vol. 20, no. 2, pp. 371373, 2006.

[11] J. Y. Yager, C. M. Jahraus, and B. H. J. Juurlink, "Dietary phase 2 enzyme inducers are neuroprotective to the immature brain following hypoxia-ischemia," Ped Research, vol. 53, no. 4, p. 24A, 2003. 
[12] B. H. J. Juurlink, "Therapeutic potential of dietary phase 2 enzyme inducers in ameliorating diseases that have an underlying inflammatory component," Canadian Journal of Physiology and Pharmacology, vol. 79, no. 3, pp. 266-282, 2001.

[13] J. W. Fahey and P. Talalay, "Antioxidant functions of sulforaphane: a potent inducer of phase II detoxication enzymes," Food and Chemical Toxicology, vol. 37, no. 9-10, pp. 973-979, 1999.

[14] J. W. Fahey, Y. Zhang, and P. Talalay, "Broccoli sprouts: an exceptionally rich source of inducers of enzymes that protect against chemical carcinogens," Proceedings of the National Academy of Sciences of the United States of America, vol. 94, no. 19, pp. 10367-10372, 1997.

[15] D. M. Minich and J. S. Bland, "A review of the clinical efficacy and safety of cruciferous vegetable phytochemicals," Nutrition Reviews, vol. 65, no. 6, pp. 259-267, 2007.

[16] S. Watanabe, X. G. Zhuo, and M. Kimira, "Food safety and epidemiology: new database of functional food factors," BioFactors, vol. 22, no. 1-4, pp. 213-219, 2004.

[17] A. Liberati, D. G. Altman, J. Tetzlaff et al., "The PRISMA statement for reporting systematic reviews and meta-analyses of studies that evaluate health care interventions: explanation and elaboration," Annals of Internal Medicine, vol. 151, no. 4, pp. W-65-W-94, 2009.

[18] T. A. Shapiro, J. W. Fahey, A. T. Dinkova-Kostova et al., "Safety, tolerance, and metabolism of broccoli sprout glucosinolates and isothiocyanates: a clinical phase I study," Nutrition and Cancer, vol. 55, no. 1, pp. 53-62, 2006.

[19] J. Figueroa, C. Blanco, A. G. Dumpiérrez et al., "Mustard allergy confirmed by double-blind placebo-controlled food challenges: clinical features and cross-reactivity with mugwort pollen and plant-derived foods," Allergy, vol. 60, no. 1, pp. 4855, 2005.

[20] E. J. Pantuck, C. B. Pantuck, and W. A. Garland, "Stimulatory effect of brussels sprouts and cabbage on human drug metabolism," Clinical Pharmacology and Therapeutics, vol. 25, no. 1, pp. 88-95, 1979.

[21] E. J. Pantuck, C. B. Pantuck, and K. E. Anderson, "Effect of brussels sprouts and cabbage on drug conjugation," Clinical Pharmacology and Therapeutics, vol. 35, no. 2, pp. 161-169, 1984.

[22] L. Ovesen, S. Lyduch, and M. L. Idorn, "The effect of a diet rich in brussels sprouts on warfarin pharmacokinetics," European Journal of Clinical Pharmacology, vol. 34, no. 5, pp. 521-523, 1988.

[23] V. Vovolis, G. Poulios, and N. Koutsostathis, "IgE-mediated allergy to raw cabbage but not to cooked," Allergy, vol. 64, no. 6, pp. 964-965, 2009.

[24] C. A. Rosen, G. E. Woodson, J. W. Thompson, A. P. Hengesteg, and H. L. Bradlow, "Preliminary results of the use of indole-3carbinol for recurrent respiratory papillomatosis," Otolaryngology-Head and Neck Surgery, vol. 118, no. 6, pp. 810-815, 1998.

[25] T. W. Kensler, J. G. Chen, P. A. Egner et al., "Effects of glucosinolate-rich broccoli sprouts on urinary levels of aflatoxin-DNA adducts and phenanthrene tetraols in a randomized clinical trial in He Zuo township, Qidong, People's Republic of China," Cancer Epidemiology Biomarkers and Prevention, vol. 14, no. 11, pp. 2605-2613, 2005.

[26] R. B. Singh, M. A. Niaz, J. P. Sharma, R. Kumar, V. Rastogi, and M. Moshiri, "Randomized, double-blind, placebo-controlled trial of fish oil and mustard oil in patients with suspected acute myocardial infarction: the Indian experiment of infarct survival-4," Cardiovascular Drugs and Therapy, vol. 11, no. 3, pp. 485-491, 1997.

[27] S. Jood, M. Gupta, S. K. Yadav, and N. Khetarpaul, "Effect of supplementation on haemoglobin and serum retinol levels and nutritional status of school children of Northern India," Nutrition and Health, vol. 15, no. 2, pp. 97-111, 2001.

[28] C. A. Rosen and P. C. Bryson, "Indole-3-carbinol for recurrent respiratory papillomatosis: long-term results," Journal of Voice, vol. 18, no. 2, pp. 248-253, 2004.

[29] M. A. Riedl, A. Saxon, and D. Diaz-Sanchez, "Oral sulforaphane increases phase II antioxidant enzymes in the human upper airway," Clinical Immunology, vol. 130, no. 3, pp. 244$251,2009$.

[30] A. T. Dinkova-Kostova, J. W. Fahey, K. L. Wade et al., "Induction of the phase 2 response in mouse and human skin by sulforaphane-containing broccoli sprout extracts," Cancer Epidemiology Biomarkers and Prevention, vol. 16, no. 4, pp. 847851, 2007.

[31] P. J. Fell, S. Soulsby, M. M. Blight, and J. Brostoff, "Oilseed rape-a new allergen?" Clinical and Experimental Allergy, vol. 22, no. 4, pp. 501-505, 1992.

[32] W. Hemmer, M. Focke, F. Wantke, S. Jäger, M. Götz, and R. Jarisch, "Oilseed rape pollen is a potentially relevant allergen," Clinical and Experimental Allergy, vol. 27, no. 2, pp. 156-161, 1997.

[33] D. Parratt, W. H. Macfarlane Smith, G. Thomson, L. A. Cameron, and R. D. Butcher, "Evidence that oilseed rape (Brassica napus ssp. oleifera) causes respiratory illness in rural dwellers," Scottish Medical Journal, vol. 40, no. 3, pp. 74-76, 1995.

[34] A. Soutar, C. Harker, A. Seaton, and G. Packe, "Oilseed rape and bronchial reactivity," Occupational and Environmental Medicine, vol. 52, no. 9, pp. 575-580, 1995.

[35] A. Soutar, C. Harker, A. Seaton, M. Brooke, and I. Marr, "Oilseed rape and seasonal symptoms: epidemiological and environmental studies," Thorax, vol. 49, no. 4, pp. 352-356, 1994.

[36] A. Lerbæk, S. C. Rastogi, and T. Menné, "Allergic contact dermatitis from allyl isothiocyanate in a Danish cohort of 259 selected patients," Contact Dermatitis, vol. 51, no. 2, pp. 79-83, 2004.

[37] F. Sakauchi, M. M. H. Khan, M. Mori et al., "Dietary habits and risk of ovarian cancer death in a large-scale cohort study (JACC study) in Japan," Nutrition and Cancer, vol. 57, no. 2, pp. 138-145, 2007.

[38] L. Y. Sue, C. Schairer, X. Ma et al., "Energy intake and risk of postmenopausal breast cancer: an expanded analysis in the prostate, lung, colorectal, and ovarian cancer screening trial (PLCO) cohort," Cancer Epidemiology Biomarkers and Prevention, vol. 18, no. 11, pp. 2842-2850, 2009.

[39] C. P. J. Caygill, A. Charlett, and M. J. Hill, "Relationship between the intake of high-fibre foods and energy and the risk of cancer of the large bowel and breast," European Journal of Cancer Prevention, vol. 7, no. 2, pp. S11-S17, 1998.

[40] A. Latif, H. J. McBurney, S. A. Roberts et al., "Breast cancer susceptibility variants alter risk in familial ovarian cancer," Familial Cancer, vol. 9, no. 4, pp. 503-506, 2010.

[41] V. Bissonauth, B. Shatenstein, E. Fafard et al., "Risk of breast cancer among French-Canadian women, noncarriers of more frequent BRCA1/2 mutations and consumption of total energy, coffee, and alcohol," The Breast Journal, vol. 15, supplement 1, pp. S63-S71, 2009. 
[42] A. Memon, A. Varghese, and A. Suresh, "Benign thyroid disease and dietary factors in thyroid cancer: a case-control study in Kuwait," British Journal of Cancer, vol. 86, no. 11, pp. 17451750, 2002.

[43] M. R. Galanti, L. Hansson, R. Bergström et al., "Diet and the risk of papillary and follicular thyroid carcinoma: a population-based case-control study in Sweden and Norway," Cancer Causes and Control, vol. 8, no. 2, pp. 205-214, 1997.

[44] J. J. Michnovicz and H. L. Bradlow, "Altered estrogen metabolism and excretion in humans following consumption of indole-3-carbinol," Nutrition and Cancer, vol. 16, no. 1, pp. 59-66, 1991.

[45] D. S. Michaud, P. Pietinen, P. R. Taylor, M. Virtanen, J. Virtamo, and D. Albanes, "Intakes of fruits and vegetables, carotenoids and vitamins $\mathrm{A}, \mathrm{E}, \mathrm{C}$ in relation to the risk of bladder cancer in the ATBC cohort study," British Journal of Cancer, vol. 87, no. 9, pp. 960-965, 2002.

[46] K. Sato, N. Kawakami, T. Ohtsu et al., "Broccoli consumption and chronic atrophic gastritis among Japanese males: an epidemiological investigation," Acta Medica Okayama, vol. 58, no. 3, pp. 127-133, 2004.

[47] K. D. Lust, J. E. Brown, and W. Thomas, "Maternal intake of cruciterous vegetables and other foods and colic symptoms in exclusively breast-fed infants," Journal of the American Dietetic Association, vol. 96, no. 1, pp. 46-48, 1996.

[48] E. Ron, R. A. Kleinerman, and J. D. Boice Jr., "A populationbased case-control study of thyroid cancer," Journal of the National Cancer Institute, vol. 79, no. 1, pp. 1-12, 1987.

[49] L. N. Kolonel, J. H. Hankin, L. R. Wilkens, F. H. Fukunaga, and M. W. Hinds, "An epidemiologic study of thyroid cancer in Hawaii," Cancer Causes and Control, vol. 1, no. 3, pp. 223 $234,1990$.

[50] S. Franceschi, A. Fassina, R. Talamini et al., "Risk factors for thyroid cancer in Northern Italy," International Journal of Epidemiology, vol. 18, no. 3, pp. 578-584, 1989.

[51] G. Wingren, T. Hatschek, and O. Axelson, "Determinants of papillary cancer of the thyroid," American Journal of Epidemiology, vol. 138, no. 7, pp. 482-491, 1993.

[52] M. A. Wessel, J. C. Cobb, E. B. Jackson, G. S. Harris Jr., and A. C. Detwiler, "Paroxysmal fussing in infancy, sometimes called colic," Pediatrics, vol. 14, no. 5, pp. 421-435, 1954.

[53] M. S. Blaiss, M. L. McCants, and S. B. Lehrer, "Anaphylaxis to cabbage: detection of allergens," Annals of Allergy, vol. 58, no. 4, pp. 248-250, 1987.

[54] F. F. Brito, P. Mur, B. Bartolomé et al., "Rhinoconjunctivitis and occupational asthma caused by Diplotaxis erucoides (wall rocket)," Journal of Allergy and Clinical Immunology, vol. 108, no. 1, pp. 125-127, 2001.

[55] E. Compés, O. Palomares, M. Fernández-Nieto, C. Escudero, and J. Cuesta-Herranz, "Allergy to turnip seeds in a bird fancier," Allergy, vol. 62, no. 12, pp. 1472-1473, 2007.

[56] C. D. Caldan, "Contact urticaria from cabbage (brassica)," Contact Dermatitis, vol. 7, no. 5, p. 279, 1981.

[57] A. Chakrabarti, L. Prais, and I. S. Foulds, "Allergic contact dermatitis to broccoli," British Journal of Dermatology, vol. 148, no. 1, pp. 172-173, 2003.

[58] C. J. Dannaker and I. R. White, "Cutaneous allergy to mustard in salad maker," Contact Dermatitis, vol. 16, no. 4, pp. 212-214, 1987.

[59] G. R. Di Giacomo, P. Boschetto, P. Maestrelli, and G. Moro, "Asthma and rhino-conjunctivitis form exposure to rape flour: a clinical case report," Medicina del Lavoro, vol. 89, no. 3, pp. 226-231, 1998 (Italian).
[60] E. Hernández, S. Quirce, M. Villalba, J. Cuesta, and J. Sastre, "Anaphylaxis caused by cauliflower," Journal of Investigational Allergology and Clinical Immunology, vol. 15, no. 2, pp. 158159, 2005.

[61] G. Jorro, C. Morales, J. V. Braso, and A. Pelaez, "Mustard allergy: three cases of systemic reaction to ingestion of mustard sauce," Journal of Investigational Allergology and Clinical Immunology, vol. 5, no. 1, pp. 54-56, 1995.

[62] A. Lingelbach, J. Rakoski, and J. Ring, "Exercise-induced anaphylaxis to cabbage and mustard," Allergy and Clinical Immunology International, vol. 15, no. 4, pp. 181-183, 2003.

[63] B. Meding, "Immediate hypersensitivity to mustard and rape," Contact Dermatitis, vol. 13, no. 2, pp. 121-122, 1985.

[64] J. S. Pasricha, R. Gupta, and S. K. Gupta, "Contact hypersensitivity to mustard khal and mustard oil," Indian Journal of Dermatology, Venereology and Leprology, vol. 51, no. 2, pp. 108-110, 1985.

[65] S. Quirce, M. F. Madero, M. Fernández-Nieto, A. Jiménez, and J. Sastre, "Occupational asthma due to the inhalation of cauliflower and cabbage vapors," Allergy, vol. 60, no. 7, pp. 969-970, 2005.

[66] N. Rosenberg and P. Gervais, "Occupational asthma and food allergy: an association of underestimated frequency," Presse Medicale, vol. 15, no. 34, pp. 1712-1714, 1986 (French).

[67] I. M. Sánchez-Guerrero and A. I. Escudero, "Occupational contact to broccoli," Allergy, vol. 53, no. 6, pp. 621-621, 1998.

[68] I. S. Schulze and U. Wollina, "Mustard allergy," Kosmetische Medizin, vol. 24, no. 2, pp. 63-65, 2003 (German).

[69] C. H. Suh, H. S. Park, D. H. Nahm, and H. Y. Kim, "Oilseed rape allergy presented as occupational asthma in the grain industry," Clinical and Experimental Allergy, vol. 28, no. 9, pp. 1159-1163, 1998.

[70] A. L. Valero, P. Amat, M. Bescos, M. Lluch, E. Serra, and A. Malet, "Mustard seed allergy: report of five cases," Revista Espanola de Alergologia e Inmunologia Clinica, vol. 10, no. 4, pp. 193-198, 1995 (Spanish).

[71] W. G. van Ketel, "A cauliflower allergy," Contact Dermatitis, vol. 1, no. 5, pp. 324-325, 1975.

[72] L. Widström and S. G. O. Johansson, "IgE-mediated anaphylaxis to mustard," Acta Dermato-Venereologica, vol. 66, no. 1, pp. 70-71, 1986.

[73] V. Zawar, "Pityriasis rosea-like eruptions due to mustard oil application," Indian Journal of Dermatology, Venereology and Leprology, vol. 71, no. 4, pp. 282-284, 2005.

[74] F. B. Walker 4th, "Myocardial infarction after diet-induced warfarin resistance," Archives of Internal Medicine, vol. 144, no. 10, pp. 2089-2090, 1984.

[75] S. J. Kempin, "Warfarin resistance caused by broccoli," The New England Journal of Medicine, vol. 308, no. 20, pp. 12291230, 1983.

[76] J. Geier, "Mustard wrap-dermatitis," Dermatosen in Beruf und Umwelt, vol. 39, no. 1, pp. 17-18, 1991 (German).

[77] V. Gutierrez-Millet, J. Navas-Palacios, J. Gomez-Reino, and J. L. Fernandez-Epifanio, "Renal involvement in toxic oil syndrome," The Lancet, vol. 1, no. 8281, p. 1120, 1982.

[78] A. Alonso-Ruiz, A. C. Zea-Mendoza, and J. M. SalazarVallinas, "Toxic oil syndrome: a syndrome with features overlapping those of various forms of scleroderma," Seminars in Arthritis and Rheumatism, vol. 15, no. 3, pp. 200-212, 1986.

[79] R. G. Phelps and R. Fleischmajer, "Clinical, pathologic, and immunopathologic manifestations of the toxic oil syndrome. Analysis of fourteen cases," Journal of the American Academy of Dermatology, vol. 18, no. 2, pp. 313-324, 1988. 
[80] M. Rodriguez, E. Noguera, and R. S. Del Villar, "Toxic synovitis from denatured rapeseed oil," Arthritis and Rheumatism, vol. 25, no. 12, pp. 1477-1480, 1982.

[81] J. R. Ricoy, A. Cabello, J. Rodriguez, and I. Tellez, "Neuropathological studies on the toxic syndrome related to adulterated rapeseed oil in Spain," Brain, vol. 106, no. 4, pp. 817-835, 1983.

[82] R. Velicia, C. Sanz, and F. Martinez-Barredo, "Hepatic disease in the Spanish toxic oil syndrome. A thirty months follow-up," Journal of Hepatology, vol. 3, no. 1, pp. 59-65, 1986.

[83] World Health Organization, Toxic Oil Syndrome: Ten Years of Progress, WHO Regional Office for Europe, Copenhagen, Denmark, 2004.

[84] A. M. Holbrook, J. A. Pereira, R. Labiris et al., "Systematic overview of warfarin and its drug and food interactions," Archives of Internal Medicine, vol. 165, no. 10, pp. 1095-1106, 2005.

[85] N. Muehlberger, S. Schneeweiss, and J. Hasford, "Adverse drug reaction monitoring cost and benefit considerations-part I: frequency of adverse drug reactions causing hospital admissions," Pharmacoepidemiology and Drug Safety, vol. 6, no. 3, pp. S71-S77, 1997. 

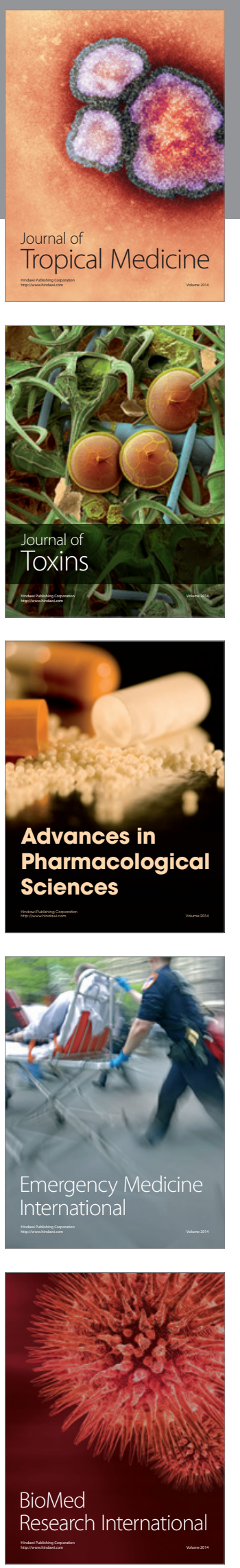
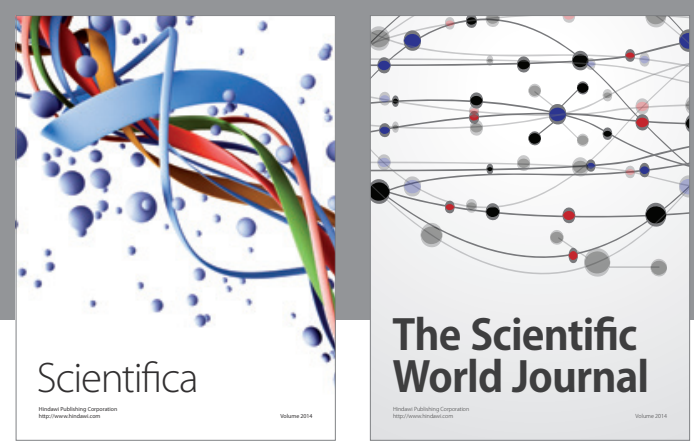

The Scientific World Journal
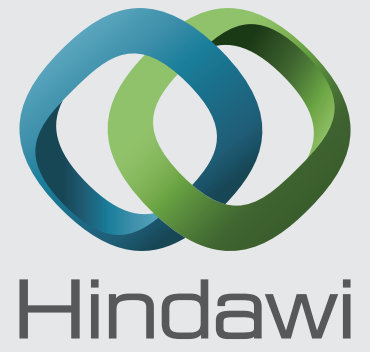

Submit your manuscripts at

http://www.hindawi.com
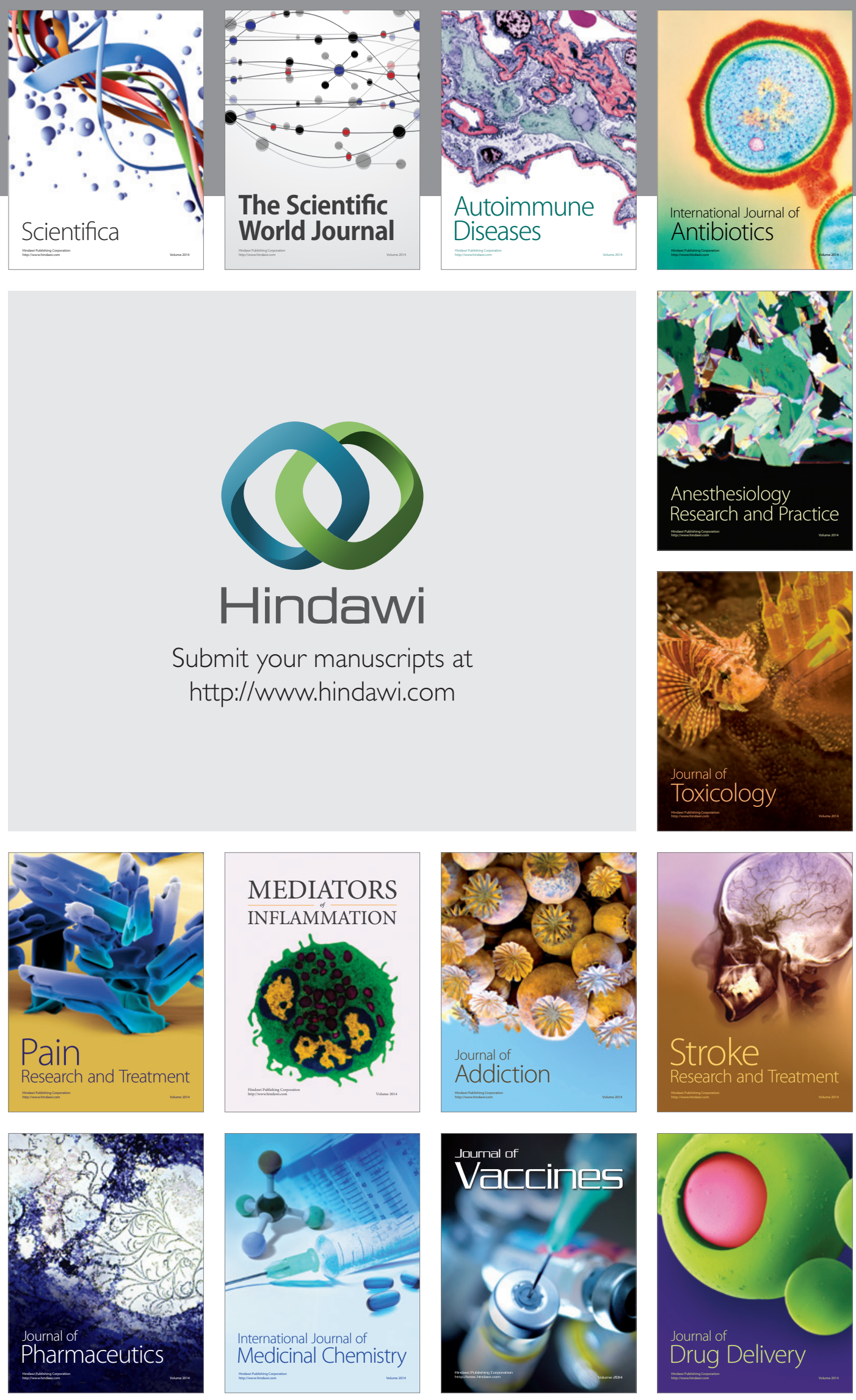